\title{
LA ESTÉTICA BRITÁNICA DEL SIGLO XVIII ${ }^{1}$
}

David SOBRevilla

INSTTTUTO GOETHE DE LIMA

\section{Introducción}

No existe un acuerdo unánime ni mayoritario sobre cuándo comienza la estética británica. Hay autores que señalan su principio con Francis Bacon (15511626) en las postrimerías del siglo XVI e inicios del XVII - a fin de cuentas Bacon escribió un pequeño ensayo "Of Beauty” (su ensayo XIIII) y tiene diversas observaciones estéticas de importancia en su famoso libro De dignitate et Augmentis Scientiarum (1623)-; así lo juzga, por ejemplo, el profesor András Horn. Otros investigadores han mostrado la significación de las ideas estéticas de Thomas Hobbes (1588-1679) y su eco en autores prestigiosos como John Dryden (1631-1700) y John Dennis (1654-1734); así procede el profesor Clarence DeWitt Thorpe en su inatendido libro The Aesthetic Theory of Thomas Hobbes (1940). Un tercer grupo prefiere situar posteriormente el comienzo genuino de la estética británica hasta Shaftesbury (1671-1713), "el primer gran pensador estetico que produjo Inglaterra" según Ernst Cassirer. ${ }^{2}$ Finalmente, el mayor conocedor de la estética británica del siglo XVII, Walter John Hipple Jr., empieza su libro The Beautiful, the Sublime and the Picturesque in Eighteenth-Century British Aesthetic Theory (1957) con el estudio de Addison (1672-1719), pues considera que el aporte de Shaftesbury a la estética es tan insignificante que no merece tenerse en cuenta.

Nuestro punto de vista sobre el particular admite matices: reconocemos que hay planteamientos estéticos considerables en la estética británica del siglo XVII —como en los mencionados Bacon, Hobbes, Dryden o Dennis-; pero nosotros hemos circunscrito nuestro estudio a la estética británica del siglo XVIII y comenzamos con Shaftesbury. Para lo primero existen motivaciones puramente accidentales: planteamos una investigación sobre este siglo, la cual tenemos intención de completar posteriormente con un examen de los planteamientos estéticos británicos en el siglo XVII, que sin duda no son tan

1 Este trabajo fue redactado en el marco de un proyecto patrocinado por el Instituto de Estudios Humanústicos de la Universidad de San Marcos en Lima, Perú. Se integra en un estudio más amplio sobre la evolución de la estética occidental.

2 Die platonische Renaiouance in England und die Schule pon Cambridge, 1932. 
importantes como la ideas posteriores -en este sentido constituye una exageración que el profesor DeWitt hable de una "teoría estética" de Hobbes, pues no la hay como tal. Pero por otro lado, existen razones de principio para poner atención en la estética británica del siglo XVIII:

Fue decisiva para el surgimiento de la estética moderna —o estética a secas, porque en rigor no hay una estética de la Antigüedad ni de la Edad Media: en esas épocas existía una "teoría de los bello y del arte". En cuanto al pensamiento renacentista, se encuentra en un movimiento de transición hacia lo moderno. Es muy significativo que la estética británica surja en coincidencia con la influencia avasalladora que ejerció Locke. Su “new way of ideas" revolucionó la filosofía inglesa y moderna, y la estética no fue la excepción al respecto, sino una ilustración más de este proceso. Fueron la ideas de Locke las que suscitaron la reacción neoplatónica de Shaftesbury y los planteamientos de Addison, Hutcheson y sus continuadores, que de distinto modo - y a veces de una manera no muy fiel- querían cumplir con las intenciones de la filosofia lockeana.

Nos parece justo comenzar este recuento de la estética británica del siglo XVIII con Shaftesbury. R. L. Brett ha subrayado sus aportaciones: haber enunciado por primera vez el principio estético del desinterés del juicio estético, haber contribuido a transformar "lo sublime" de una idea retórica en una idea estética y haber postulado un sentido interno de la belleza - aunque se trate de una solución ambigua al problema del gusto. ${ }^{3}$ No es poca cosa: se trata de aportes tangibles y de importancia, que no pueden ser minimizados ni ignorados.

Una última observación: hablamos de la estética británica y no de la estética inglesa del siglo XVIII, porque en aquel entonces no eran importantes tan sólo las ideas inglesas sino también la escocesas. Quizás sea excesivo, por otra parte, hablar de una escuela británica de filosofia; pero es sensato hacerlo si se opone a la filosofía continental -que tiene a su vez distintas tradiciones, como el racionalismo francés o la metafisica alemana.

\section{El conde de Shaftesbury}

Antony Ashley Cooper, tercer conde de Shaftesbury, nació el 26 de febrero de 1671 en Exeter Home, Londres, y falleció el 13 de febrero de 1713 en Nápoles. Su cuidadosa educación fue dirigida por John Locke. En 1695 ingresó al Parlamento como miembro de los Whigs y continuó en la actividad política hasta 1703. Se retiró de ella debido al desfavor de su partido y a razones de salud y se dedicó a escribir. Su mayor obra lleva por título Characteristics of Men, Manners, Opinions and Times (2 volúmenes, 1711 ), a la que hay

3 Cfr. el libro de Brett, La filosofia de Shaftesbury y la esterica literaria del siglo XVUI, 1951. 
que agregar para la estética la colección de artículos, editada póstumamente, Second Characters or the Language of Forms (1914).

Filosóficamente, el puesto que corresponde a Shaftesbury es el de discípulo de los filósofos neoplatónicos de Cambridge - Ralph Cudwoth, Henry More, John Norris- y el de impugnador de las filosofias de Hobbes y de su predecesor Locke. Combate el mecanicismo, egoísmo y relativismo que cree hallar en el pensamiento del primero, el voluntarismo que el segundo atribuye a Dios y que coloca como fundamento de la moralidad, la justicia y la equidad; y el empirismo de ambos en materia psicológica, frente al cual opone el poder creador de la mente, que sería dueña de principios innatos.

Siguiendo la tradición griega y medieval, sostiene Shaftesbury que hay una unidad entre lo bello, lo verdadero y lo bueno. Los grados de la belleza son tres: el primero es el de la belleza suprema y soberana principio, origen y fuente de toda belleza, que no sólo contiene meras formas, sino además formas plásticas. El segundo grado es el de las formas en la naturaleza y en el hombre, que proceden con inteligencia, acción y operación, albergando en sí las formas que son un efecto de la mente y la mente misma. Y por último hay la belleza de la formas inertes o muertas, producidas por el artista o por la naturaleza, sin poder formativo, acción ni inteligencia en ellas.

El artista debe formar como la naturaleza, pero no imitándola servilmente en todos sus detalles, sino más bien produciendo como una segunda naturaleza: constituyendo la obra de arte con una estructura interna, con independencia y con unidad y claridad de concepción que permitan visualizarla con facilidad. Para ello, debe fijar su mirada en los números interiores que regulan la simetría, y producirá entonces una obra que posea una proporción exterior. Ello se debe a que toda simetría externa remite a otra mayor y más feliz en la mente, y toda belleza física se fundamenta en la de los números.

Percibimos los números interiores gracias a un sentido interno que podemos cultivar, convirtiéndonos en virtuosi, en virtuosos, de grado superior. La finalidad de la formación del gusto no es, en efecto, otra cosa que pasar de las preferencias accidentales y falsas a aquellas guiadas por ciertos modelos de perfección y racionales. Pues el goce de la belleza que experimenta el hombre es esencialmente racional y no sensible.

Pero en el campo de la estética, los méritos de Shaftesbury no se restringen a haber colaborado en un cierto "revival" del platonismo en la Inglaterra del siglo XVIII, polemizando contra el empirismo, sino que consisten también en haber enunciado con claridad el principio del desinterés de la "experiencia" estética y en haber contribuido a transformar "lo sublime" de idea retórica en estética. Según Shaftesbury, el goce que proporciona la belleza es plenamente desinteresado y reposa en el objeto que lo suscita. Los cuatro ejemplos que ofrece son los siguientes: nos sentimos impresionados por la belleza del 
océano sin intentar dominarlo, contemplamos embelesados un valle sin requerir para ello ser sus propietarios, nos sentimos encantados con la belleza de los árboles a cuya sombra descansamos sin desear saborear sus frutos y admiramos las formas humanas sin que provoquen en nosotros apetencias vehementes. En cambio, los animales son incapaces de conocer la belleza y de disfrutar de ella, porque no pueden percibir las formas de las cosas, sino sólo lo que está bajo ellas: el sabor de la hierba con la que satisfacen su hambre o el del agua con la que sacian su sed. El goce desinteresado de la belleza permite al hombre escapar de sus afecciones privadas o egoístas, que según Hobbes son las únicas afecciones humanas. Puede así reconocer la dignidad de las cosas o de los otros hombres, con lo que la experiencia de lo bello contribuye a elevar al hombre y al mundo y a posibilitar la vida social.

La traducción de Boileau del tratado de Longino Sobre lo sublime en 1674 y la publicación de sus propias Reflexiones sobre Longino en 1675 pusieron de moda no sólo en Francia sino también en Inglaterra el discurso sobre lo sublime como una forma de calificar ciertos rasgos estilísticos o un estilo peculiar. También Shaftesbury emplea la palabra "sublime” en este sentido para referirse a un estilo en que la fusión de los sentimientos y pensamientos elevados presta al lenguaje una elocuencia admirable e inanalizable. No obstante, "la importancia de Shaftesbury [...] no consiste en su estudio del estilo, sino en su contribución a transfórmar. 'lo sublime' de idèa retórica en estética. [...] Antes de Shaftesbury la palabra 'sublime' se aplicaba casi siempre a factores de estilo; después de la publicación de las Characteristics, significaría cada vez más cierta clase de emoción específica frente a lo terrible y grandioso" (R. L. Brett). Así Dios, “espíritu sublime celestial”, vivifica según nuestro autor a la naturaleza transformándola en algo sublime.

\section{Joseph Addison}

Nació en Milston el lo. de mayo de 1672 y falleció en Londres el 17 de junio de 1719. Estudió en' el Queen's College de Oxford y recibió en 1699 una pensión real que le permitió viajar durante cuatro años por Francia, Italia y Alemania. Fue miembro del Parlamento como partidario whig y en 1711 fundó, conjuntamente con su compañero de estudios Richard Steele, el periódico The Spectator. Allí publicó una serie de artículos que lo darían a conocer como uno de los mejores ensayistas ingleses de su época. Su colaboración con Steele cesó al casarse en 1716.

Los artículos de Addison que interesan a la historia de la estética son los publicados en The Spectator del 21 de junio al 3 de julio de 1712 bajo el título general de "Los placeres de la imaginación". Según Addison, así como existe un gusto sensible, hay otro mental, que es "aquella facultad del alma que discierne las bellezas de un autor con placer y la imperfecciones con desagrado”. Tres 
son los criterios para saber si una persona tiene gusto: "la prueba del tiempo" (denominación propuesta en nuestros días por el filósofo Peter Kivy), es decir, si se siente deleitada por los grandes autores antiguos y modernos; la prueba de saber distinguir las cualidades o perfecciones específicas de un autor; y la de resultar afectada por la forma lingüística en que es expuesta una idea por un gran escritor o por un genio ordinario. Si se posee gusto, se puede cultivarlo leyendo a autores galanos, conversando con los hombres de genio refinado o estudiando las grandes obras de crítica literaria.

Prosiguendo una larga tradición de la Antigüedad, sostiene Addison que la vista es el sentido más perfecto y agradable a todos, y que proporciona ideas a la imaginación. Por placeres de la imaginación o fantasía entiende los que nacen de los objetos visibles, ya sea que los tengamos actualmente ante nuestra vista (placeres primarios), o que convoquemos las ideas a nuestra mente gracias a las pinturas, estatuas, descripciones o a cualquier otra cosa semejante (placeres secundarios). Los placeres de la imaginación se distinguen de los de los sentidos por no ser tan groseros, y de los del entendimiento por no ser tan refinados. Son más obvios, más fáciles de adquirir y más saludables que estos últimos, ya que no exigen una labor excesiva del cerebro; y elevan al hombre por sobre el mundo de los sentidos, pues son desinteresados y llevan a descubrir encantos ocultos.

Las fuentes de los placeres primarios de la imaginación son la visión de lo grandioso, inusal y bello. Por grandeza entiende Addison no el tamaño de un objeto singular, sino la amplitud de una visión íntegra considerada como una pieza entera. Tal es el caso de la contemplación de una campiña abierta, de un desierto, de una masa montañosa, de un panorama rocoso y de precipicios. La explicación del placer que provoca la grandeza $\longrightarrow$ lo sublime en el lenguaje habitual del siglo XVIII- es, según Addison, que "Nuestra imaginación ama encontrarse llena con un objeto o aprehender algo demasiado grande para su capacidad. En tales visiones ilimitadas nos sentimos arrojados a una admiración placentera; y, al captarlas, experimentamos una tranquilidad y sorpresa deleitosas en el alma." En cambio, la fantasía se siente a disgusto al encontrarse confinada o estrecha. Ia grandeza es para Addison un placer más propio de lo natural que de lo artístico (Samuel H. Monk).

Según el autor, toda cosa nueva o infrecuente origina un placer en la imaginación "porque llena el alma de una sorpresa agradable, gratifica su curiosidad y le da una idea que no poseía anteriormente". Lo nuevo o inusual introduce variedad en nuestra vida y contribuye a divertir nuestra mente con la extrańeza de su apariencia; de ahí el encanto que provoca lo monstruoso y lo deforme. Quiebra, además, la monotonía de lo acostumbrado, como sucede con los cambios en el paisaje o de las estaciones.

Pero el camino que más directamente conduce el alma hacia los placeres de la imaginación es el de la belleza, que difunde de inmediato una secreta 
satisfacción y complacencia, otorgando una acabamiento a toda cosa grande o infrecuente. Addison encuentra que no hay una belleza absoluta, sino sólo relativa a cada especie; pero comprueba, asimismo, que "Hay una segunda clase de belleza que hallamos en nuestros productos del arte y la naturaleza y que no trabaja en la imaginación con el color y la belleza que aparece en nuestra propia especie, pero que sin embargo es apta para despertar en nosotros un deleite secreto y una suerte de predilección por los lugares u objetos en los cuales la descubrimos. Consiste en la alegría o variedad de colores, en la simetría o proporción de las partes, en el arreglo y disposición de los cuerpos, o en la mezcla y concurrencia correcta de todos estos elementos. Entre todas estas clases de belleza el ojo se deleita sobre todo con el color." La belleza en general — diferente de la de la propia especie- está compuesta por las viejas notas tradicionales: color, simetría, composición y por la mezcla adecuada de estos elementos.

Según Addison, para poder decubrir qué causa en nosotros los placeres de la imaginación, deberíamos conocer la naturaleza de las ideas y la sustancia del alma humana; así estaríamos en condiciones de determinar cómo concuerdan la grandeza, novedad o belleza con nuestra sustancia anímica; pero como, de acuerdo con Locke, lo ignoramos, no tiene sentido tratar de indagarlo. En cambio, sí lo tiene preguntar con qué finalidad somos afectados de esta manera. No debemos, pues, averiguar las causas necesarias y eficientes de los placeres de la imaginación, sino las causas finales. La de la grandeza es que Dios ha hecho nuestra alma de tal modo que sólo la contemplación de su inmensidad e ilimitación puede satisfacerla. La de la novedad reside en que él nos ha querido impulsar así a la búsqueda del conocimiento y gratificarnos por las penurias que esta investigación nos depara. La de lo bello de la especie es provocar la multiplicación de la misma, y la de lo bello en general, la conexión entre la creación divina y el deleite que nos causa.

Las obras de la naturaleza son, según nuestro autor, más placenteras que las del arte por su vastedad e inmensidad; pero aumentarán aún más el deleite que ocasionan si, a la fruición que provocan a los ojos, añaden el de poder ser comparadas con el de las obras artísticas. Éstas, a su vez, serán tanto más bellas, cuanto más recuerden a sus modelos naturales perfectos.

Las fuentes de los placeres secundarios de la imaginación son sobre todo cuatro: la escultura, la pintura, la descripción y la música. La primera constituye la representación más natural y la que nos muestra algo lo más parecido posible al objeto representado. La pintura es menos fiel a su original, porque, al tener sólo dos dimensiones, no permite apresar sus sinuosidades e irregularidades. Aún más se aleja de lo representado la descripción: sus elementos (las letras y sílabas) son desemejantes al original al que se remiten y las palabras de un lenguaje son comprendidas sólo por pueblos y naciones determinadas. Finalmente la música se encuentra en la situación más desfavorecida y extrema: 
los sonidos son todavía menos aptos para reproducir los objetos visibles, dado que no tienen ideas anexas que permitan hacer una descripción.

Al igual que en el caso de los placeres primarios de la imaginación, tampoco en los secundarios podemos indicar su causa necesaria, sino tan sólo la final: animarnos y alentarnos en la búsqueda de la verdad.

A continuación, Addison se refiere más en detalle a los placeres secundarios de la imaginación provocados por las palabras, sobrentendiendo que lo pertinente a ellos se puede aplicar también a la pintura y escultura. Cuando son bien escogidos, los vocablos tienen un gran poder sobre la fantasía, porque el poeta nos ofrece una descripción muy animada con una visión libre de lo que a él le place y descubre a su público partes de la naturaleza a las que habitualmente éste no atendería. Que las mismas descripciones complazcan de diferente manera a distintos lectores, se debe que éstos han desarrollado en grados diversos sus gustos o a que asocian ideas variadas a las mismas palabras.

Un gran poeta tiene que nacer con una imaginación poderosa y debe esforzarse y sacrificarse por cultivarla. Homero la ha desarrollado con relación a la grandeza, Virgilio con respecto a lo bello, Ovidio a lo nuevo y Milton a estas tres cualidades en conjunto.

Los placeres secundarios de la imaginación son más amplios y universales que los primarios, ya que, mientras lo desagradable repugna a la vista, una descripción apta puede convertirlo no sólo en tolerable sino en entretenido y aun placentero. Sucede así, por ejemplo, con la imagen de un estercolero realizada con las expresiones adecuadas - aunque se pueda objetar que el placer resultante sea más intelectual que imaginativo. De esta manera, en el caso de la literatura a ias tres fuentes de los placeres primarios - lo grandioso, lo bello y lo novedoso- se agrega una cuarta: lo desagradable. Esta nueva categoría posibilita explicar por qué son placenteras las descripciones de lo terrible y de lo fantástico: en aquéllas nos sentimos rozados por el peligro, pero nos sabemos con seguridad; en éstas, al rememorar las historias que hemos escuchado en nuestra infancia se despiertan en nosotros los temores y aprehensiones secretas a las que la mente humana se encuentra sometida naturalmente. Los modernos sobrepujan a los antiguos en cuanto a narraciones fantásticas y los ingleses sobresalen entre los modernos.

Addison concluye su ensayo indicando que la imaginación está sujeta tanto a placeres como a sufrimientos - suscitados por los objetos contrarios a aquellos que la deleitan-, y manifiesta que debido a ella puede el hombre recibir una gran medida de felicidad o miseria.

\section{Francis Hutcheson}

Francis Hutcheson nació en Drumalig (Irlanda) el 8 de agosto de 1694 y falleció en Glasgow en 1746. Estudió en la universidad de esta última ciu- 
dad, fue ministro de la iglesia presbiteriana en Ulster, profesor de una academia presbiteriana en Dublín y, desde 1730, profesor de filosofía moral en la Universidad de Glasgow. Contó entre sus alumnos a Adam Smith y a David Hume. Su obra principal es su $A n$ Inquiry in the Original of our Ideas of Beauty and Virtue; in Two Treatises... (1725), aunque hay que mencionar también para la historia de la estética sus Reflections upon Laughter. . . (1750).

El lugar histórico-filosófico que corresponde a Hutcheson es de sucesor de Locke, Shaftesbury y Addison. Del primero, adoptó el método: el nuevo camino de las ideas lockeano concebido como un programa filosófico (J. Stolnitz); del segundo, su actitud frente a la estética, al considerarla un tema no sólo respetable, sino aún más: central para la filosofia; y del tercero, la atención que concedió a los "placeres de la imaginación" y a algunas de sus distinciones -como la de la "belleza", "novedad" y "grandeza" o sublimidad.

La Inquiry está dividida en un prefacio y dos tratados. El prefacio comienza manifestando que no hay parte de la filosofía más relevante que el conocimiento de la naturaleza humana y de sus distintos poderes y disposiciones. La importancia de cualquier verdad reside en su eficacia para hacer feliz al hombre o para proporcionarle el placer más grande y duradero. De ahí, sostiene Hutcheson, que haya efectuado una indagación de los distintos placeres que es capaz de recibir la naturaleza humana. Al reflexionar sobre nuestros sentidos externos nos es evidente que nuestras percepciones de placer o dolor no dependen directamente de nuestra voluntad, sino de la constitución de nuestra naturaleza, que da lugar a que algunos objetos nos complazcan y otros nos causen un sentimiento de insatisfacción. Algo semejante ocurre con los objetos inmateriales. Así, en el caso de la belleza o de la armonía, poseemos un sentido interno que hace que frente a ciertas cosas percibimos placer con independencia de nuestra voluntad, de si lo queremos o no. El placer no nace aquí de la captación sensible habitual de ideas como el color, sonido o el modo de la extensión, sino de la aprehensión de formas complejas como la uniformidad, el orden, el arreglo, la imitación. El sentido interno de la belleza es natural a todos los hombres y es por ello que encontramos un acuerdo tan grande entre éstos en su gusto por las formas. Algo parecido sucede en el caso de la virtud, para percibir la cual tenemos otro sentido interno. El sentido interno de la belleza y de la armonía lo estudia Hutcheson en el primer tratado y el de la moral en el segundo.

A las notas mencionadas del sentido de la belleza - 1 ) independencia de la voluntad y 2) surgimiento del placer de la percepción de formas complejas-, hay que agregar las siguientes: 3 ) innatismo, entendido como la capacidad virtual - no actual - de poder efectuar distinciones estéticas; 4) independencia del conocimiento; 5) inmediatez; 6) desarrollo a nivel humano y no animal, y 7) desinterés - las cinco primeras notas han sido enumeradas por Peter Kivy. 
Quisiéramos añadir que en otras obras Hutcheson multiplicó los sentidos internos - considerando por ejemplo el sentido del honor, de la gracia, de la concordancia, etc. La razón para esta proliferación de los sentidos internos es, señala el profesor Kivy, que nuestro autor había trasladado el modelo lockeano de las percepciones externas a la captación de la belleza y la virtud y que, al encontrar otras experiencias que parecían participar de los rasgos de la aprehensión sensible, se vio obligado a decretar la existencia de un número más amplio de sentidos internos.

Pasemos ahora a examinar detalladamente el primer tratado -el único del que nos ocuparemos. Hutcheson precisa inicialmente que la belleza es una idea originada en nosotros, y que el sentido de la belleza es nuestro poder de recibir esta idea que tiene que ver con la vista. De manera semejante, la armonía es otra idea nuestra que tiene que ver con el oído. ¿Cuál es la ocasión inmediata de esta idea? Es lo que va a tratar de determinar el autor. En su opinión, en la "experiencia" de lo bello o de lo armónico encontramos ideas simples, como las del color o del sonido, pero lo decisivo son en verdad las ideas complejas subyacentes, como las del orden y de la armonía. Llamamos sentidos externos a la capacidad de percibir las primeras, y sentido interno al poder de captar las últimas. En el sentido interno intervienen no sólo los sentidos superiores como la vista o el oído, sino además la mente, que es el poder de comparar ideas u objetos y establecer sus relaciones. Los animales podrán tener sentidos externos más agudos que los humanos, según Hutcheson; pero, como carecen de intelecto, no podrán captar ni la belleza ni la armonía.

De lo anterior parece colegirse que lo bello es una idea compleja, que posee el rango de una cualidad secundaria - pues al ser provocada en nosotros por objetos conciertas propiedades, surge en verdad de nuestra actividad mental-y que tiene una carácter placentero. Hutcheson distingue luego entre la belleza original o absoluta y la relativa. Por la primera hay que entender là que percibimos en los objetos cuando no los comparamos con nada externo, de-lo cual serían una imitación o una copia, lo cual sucede con los productos de la naturaleza, con losiobjetos intelectuales - como las teorías filosóficas y lós teoremas científicos- y con las obras artísticas. En contradicción con lo que ha sostenido antes, Hutcheson afirma que las figuras que excitan en nosotros la idea de una belleza absoluta son aquellas en las cuales hay una cierta úniformidad en la variedad - lo que constituye una cualidad real de los objetos. Así, resultaría que el triángulo es menos bello que el cuadrado, pues esta última figura tiene mayor variedad en la unidad. Dada igual uniformidad en dos figuras, la unidad incrementaría la belleza y a la inversa. La importancia de lo múltiple presentado unitariamente es confirmada, según Hutcheson, por el juicio de los niños que sienten una inclinación por las figuras regulares que son lo suficientemente simples como para dejarse aprehender con facilidad. Posteriormente el autor trata con cierto detalle de la belleza absoluta en 
los productos artísticos, en los objetos intelectuales y en las obras de arte. En todo este tratamiento se advierte la oscilación indicada entre el afán de hacer de la belleza una idea y el de seguir sosteniendo, como en la Antigüedad, que es una cualidad real.

La belleza relativa, comparativa o de designio, es la que percibimos en los objetos comúnmente considerados como imitaciones de alguna otra cosa o parecidos a ella. Esta belleza "está fundada en la conformidad o en una suerte de unidad entre el original y la copia. El original puede ser algún objeto en la naturaleza o alguna idea establecida; porque si hay alguna idea conocida como una norma y regla para fijar esta imagen o idea, podemos hacer una imitación bella". Esto es lo que sucede con la obras de artes pictóricas, escultóricas y poéticas. Sin embargo, no es un requisito que haya una belleza (absoluta) en el original para que exista una belleza relativa en la copia, pues nos consta que muchos paisajes naturales no poseen el atractivo de los cuadros o de las descripciones que se hacen de ellos. Pero, evidentemente, cuanto más bello sea el original tanto más bella será la copia. Aunque pudiera parecer extraño, la belleza relativa se da para Hutcheson no sólo en las obras de arte, sino también en los objetos naturales; lo que se torna comprensible cuando se toma en cuenta que nuestro autor era un deísta, que consideraba a la naturaleza como la obra de arte par excellence, reveladora de la intenciones y designios de Dios. En cualquier caso, como tenemos una inclinación muy fuerte en nuestra mente a comparar todas las cosas, una obra de arte está en condiciones de representar cualquier objeto, aun los más remotos, en especial las pasiones y las circunstancias de la vida humana, con las que nos sentimos más comprometidos. Aquí desempeña un gran papel la relación entre los caracteres representados y el sentido interno moral: lo ético es más conmovedor que lo natural. Pero esto no debería llevar a los artistas, digamos a los poetas, sostiene Hutcheson, a describir tan sólo los caracteres perfectos. En verdad, el artista tiene que guardar el término medio entre la representación de la belleza natural y la de la belleza perfecta idealizada.

A diferencia de lo que sucede con los sentidos externos, que nos proporcionan placeres pero también dolores, Hurcheson cree que el sentido interno de la belleza sólo nos deleita, pero sin provocar disgustos, ya que, al igual que una parte de la tradición, sostiene el autor que la fealdad es en realidad inexistente: es tan sólo una carencia o, en todo caso, una deficiencia de la belleza que esperamos en cada especie. En el fondo, ninguna forma parece ser desagradable en sí misma sino tan sólo comparativamente.

De acuerdo con Hutcheson el sentido interno de la belleza está universalmente repartido en toda la humanidad. Esto no significa negar que pueda ser acrecentado por la costumbre, la educación y el ejemplo, y contrabalanceado por el interés. El diferente grado de desarrollo del sentido interno ha sido empleado a veces como un argumento en contra de su existencia. En vano, 
porque el amor a la regularidad que se observa en todos los países y en todas las épocas muestra que, más allá de las diversas imágenes de la belleza, es la uniformidad la que constituye el fundamento universal para nuestra aprobación de las formas bellas. Mas sin tenerlo en cuenta, se ha convertido en un lugar común aceptar como algo evidente la existencia de los sentidos externos y negar la existencia del sentido interno de la belleza. La razón es, en gran parte, aunque pueda parecer sorprendente, de carácter lingüístico; contamos con nombres para designar la vista, el oído, el gusto, el olfato y el tacto, pero no para el sentido interno de la belleza. Admitir la universalidad de este sentido no significa aceptar la existencia de ideas innatas -en este caso con referencia a la belleza-; ya hemos dicho que sólo tenemos virtualmente la capacidad de realizar distinciones estéticas, pero que debemos ejecitar este poder. ¿A qué se debe la diversidad innegable de los juicios sobre la belleza? En primer lugar, a las asociaciones de ideas que nos han hecho establecer conexiones distintas y cambiantes en los distintos grupos entre los mismos objetos externos y nuestras ideas; en segundo lugar, a las diferencias entre las costumbres de los hombres; en tercer lugar, a la diversa educación que hemos recibido. Éstos son algunos de los factores operantes aquí.

A partir de la belleza y la regularidad de los efectos en la naturaleza, ¿se puede colegir el designio y sabiduría de Dios como su causa? Según Hutcheson, como podemos comprobar una correspondencia entre nuestros gustos y la disposición del sistema agradable a ellos, hay que inferir, a contrario, que debe haber un designio a este respecto en la causa del todo. Como esta conclusión ha sido extraída en forma muy apresurada, hay que completarla mediante otras pruebas. Una de ellas es que es absurdo presuponer que un agente que actuara sin ningún designio o intención hubiera podido poner en movimiento la materia y ordenarla. Este agente posee sin duda una sabiduría; lo acredita la belleza de sus manifestaciones, el que podamos subsumir la variedad de efectos bajo una sola causa y el que sea una única volición divina la que, como una sola causa general, produce una multitud de resultados particulares.

Hutcheson termina su primer tratado preguntándose por la importancia de los sentidos internos en nuestra vida y por sus causas finales. Estos sentidos nos gratifican tanto, y aún más, que los placeres sensibles, pero sin dañarnos: de ahí se relevancia. En cuanto a las causas finales de los sentidos internos, el autor se pregunta: 1) ¿qué razones han podido mover a Dios para establecer una conexión como la existente entre los objetos regulares y el placer que acompaña a nuestras percepciones de ellos; 2) ¿qué razones han podido influirlo para poder crear el mundo lleno de regularidad y armonía, tal como es en el momento presente? Para responder a la primera pregunta, Hutcheson plantea que hay que presuponer la siguiente: i) para seres dotados de un entendimiento y poder limitados, el modo de conocimiento más apropiado es el 
que va de lo universal a lo particular; ii) los objetos regulares son más fáciles de comprender y de retener que los irregulares; iii) seres de entendimiento limitado, como los hombres, deben elegir -cuando actúan racionalmenteoperar con los medios más simples y estudiar los objetos regulares, y iv) el placer depende de la constitución voluntaria del ser humano adaptada a preservar la regularidad del universo, constitución que para el Agente Supremo es el resultado no de una necesidad que le hubiera sido impuesta, sino de una libre elección. Aceptados estos presupuestos, Hutcheson sostiene que para la bondad de Dios hay una necesidad moral de conectar la belleza con el placer. De otro modo, y si fueran los objetos irregulares y las verdades particulares los que nos complacieran, se produciría una incongruencia en nuestra naturaleza: intelectualmente aprehenderíamos con más facilidad los objetos regulares y universales, pero estos entes nos causarían displacer y desagrado. Es la posibilidad contraria la cierta: que lo proporcionado y lo universal nos causa placer. De aquí se desprende la respuesta a la segunda pregunta: "ya que la divina bondad $[\ldots]$ ha constituido nuestro sentido de la belleza tal como es, [...] puede haber determinado también al Gran Arquitecto a adornar este estupendo teatro de una manera agradable a los espectadores, y la parte expuesta a las observaciones de los hombres de modo que fuera placentera a ellos". Con estas palabras concluye el primer tratado de la Inquiry de Hutcheson.

\section{David Hume}

Nació en Edimburgo (Escocia) el 26 de abril de 1711 y falleció ahí mismo el 25 de agosto de 1776. Luego de cursar estudios universitarios en su ciudad natal, viajó a París y se instaló en La Flèche, donde escribió el Tratado de la naturaleza humana - publicado en Londres en 1739. El libro cayó en el vacío y Hume no llegó a ser conocido sino con sus Ensayos de moral y politica (en la segunda edición de 1742). Se postuló dos veces, infructuosamente, para una cátedra de la Universidad de Glasgow. Fue bibliotecario, secretario en París de lord Hatford y, de modo fugaz, subsecretario del Ministerio de Relaciones Exteriores en Londres.

Hume no ha dedicado ninguna gran obra a la estética, sino que sólo hay alusiones a los temas de ésta en su Tratado... y en sus Investigaciones sobre el entendimiento humano y sobre los principios de la moral (1758; la primera investigación se publicó con otro título en 1748 y la segunda en 1751). También consagró algunos ensayos a la estética, de los cuales el más famoso e importante es "De la norma del gusto" (1757).

Antes de referirnos a la concepción humeana de lo bello y del arte quisiéramos indicar la gran importancia que nuestro autor asigna a la imaginación. Hume emplea la palabra 'imaginación' en dos sentidos: según su concepción general, la imaginación consiste en la facultad o en el poder de formar, unir y 
separar ideas. Otro sentido del vocablo es la actividad de suponer cosas que no podemos percibir actualmente (Jan Wilbanks). Hume manifiesta: "Cuando opongo la imaginación a la memoria, me refiero a la facultad por la que formamos nuestra ideas más débiles. Cuando la opongo a la razón, me refiero a la misma facultad, sólo que excluyendo nuestros razonamientos demostrativos y probables. Y cuando no la opongo a ninguna de estas facultades, puede tomarse indiferentemente en el sentido más amplio o en el limitado o, por último, el contexto explicará suficientemente el significado" (Tratado...). Es en la segunda acepción que la imaginación interesa a la estética, pues posee una carácter inventivo y en ocasiones caprichoso. En el tercer sentido corresponde a la facultad que transfiere la vivacidad de la impresión a la idea: “[La] imaginación libre y creadora, pero sin fuerza persuasiva, se opone a [la] que produce la vividness y la creencia que nos liga al mundo real. Ésta se remite al mundo de los hechos, aquélla crea las 'ficciones'. La primera difunde su actividad en sucños falaces, la otra concentra sus fuerzas en una impresión de vida concreta. El único punto que las dos concepciones tienen en común es la oposición a la razón en el sentido estricto del término, es decir, a la sola facultad de trascender, en el knowledge, tanto a la creación fantasiosa como a la creencia: es poca cosa" (O. Brunet). Entre estas dos clases de imaginación no hay una diferencia esencial, sino tan sólo de grado. En Hume hay pues tres planos de la actividad mental: primero, el del entendimiento puro, del knowledge y la certeza, el de las relaciones absolutas entre ideas abstractas; segundo, el de la creencia producida esencialmente por la estabilidad de elementos causalmente enlazados entre sí; y tercero, el de la fantasía y el sueño formado de elementos libres y poco estables que corresponden únicamente a un débil grado de probabilidad, o sea, a una creencia inferior o degenerada. La imaginación desempeña un papel en el segundo y tercer planos, entre los cuales -entre las realidades y los sueños-oscila la obra de arte.

Hume se refiere a la belleza sobre todo en el Tratado..., en su ensayo "El escéptico" (1742), en su An Inquiry concerning the Principles of Moral (1751) y en "De la norma del gusto". Éstos y otros textos, permiten reconstruir su concepción de la belleza y de la fealdad. Existe, en su opinión, una belleza natural, otra artística y una moral - y, en correspondencia, una fealdad en estos tres órdenes-; para simplificar nuestra exposición trataremos sólo de la belleza. Lo que tienen en común es la aptitud (fitness) para producir placer. En la percepción de la belleza natural cumple un papel capital el gusto o sentimiento, mientras que en la de la belleza artística y moral la razón puede corregir el falso gusto o sentimiento gracias al empleo de argumentos o de la reflexión. Sólo muy someramente se ha referido Hume a la belleza moral, echando mano de la idea ciceroniana del decoro: "El decoro, o una consideración propia de la edad, el sexo, el carácter y la situación en el mundo, puede ser clasificado entre las cualidades que son inmediatemente agradables 
a los otros, y de esta manera es elogiada y aprobada" (Los principios de la moral). Indecoroso es, en cambio, un comportamiento inconveniente, como por ejemplo el afeminamiento en el hombre o la rudeza en la mujer. Pero si aquí cabe una explicación, no sucede lo mismo en el caso del encanto de algunos seres humanos, que es algo en verdad inefable.

La belleza externa de los seres naturales y de las obras de arte no es una cualidad real que se encuentre en ellos, sino que reside en la aptitud que tienen para provocar en nosotros el sentimiento de una placer calmo. Por lo tanto, la belleza requiere que dichos seres y obras posean la forma adecuada, y que a su vez el espectador tenga la estructura mental necesaria para experimentar este sentimiento. Veamos estos requerimientos en el caso del objeto y del sujeto.

Según Hume, el placer que nos causa la belleza de todos los objetos visibles es en buena parte el mismo, a pesar de que a veces deriva del mero aspecto y modo de manifestarse de los objetos y, otras, de la simpatía e idea de su utilidad (Tratado...). En el primer caso, es la apariencia de los objetos la que provoca el placer de lo bello: en la figuras simples, su mera forma, y en las compuestas, la totalidad de su estructura al actuar sobre la sensibilidad humana. Pero no hay, según Hume, figuras geométricas perfectas o bellas en sí; y no se trata tampoco de que sea la percepción de relaciones ocultas la que hace surgir el sentimiento de la belleza. En el segundo caso, son la simpatía y la idea de la utilidad de los objetos las que producen el placer de lo bello. En contra de la opinión imperante en su tiempo, que sostenía que la belleza y la utilidad se excluían mutuamente, afirma Hume que ésta constituye esencialmente a aquélla, tanto en el caso de los seres naturales como en el de las obras de arte: el vigor de un caballo y el orden de un palacio contribuirán a hacerlos hermosos. La simpatía produce el placer de lo bello de una manera más sutil. Su mecanismo psicológico reposa, de acuerdo con Hume, en nuestra interpretación de los sentimientos del otro. Los seres de la naturaleza o las obras de arte pueden causar en nosotros el placer de lo bello, porque interpretamos los sentimientos de su poseedor y nos sentimos agradados por la satisfacción que él muestra en el objeto poseído. Se trata de un placer provocado por la imaginación que nos saca de nuestro interés propio y nos hace entrar en el ámbito del del otro - ya sea que tengamos una relación de amistad con él o no. En el caso de los seres humanos "el elemento principal de la belleza personal consiste en una aire de salud y vigor, y en una disposición tal de los distintos miembros que promete fuerza y actividad. Esta idea de la belleza no puede ser explicada sino por medio de la simpatía” (Tratado...).

Hume no explica en detalle por qué el orden o la construcción de las partes de un objeto provoca el placer de lo bello, sino que sostiene en forma escueta -aplicando una idea de Hutcheson- que ello puede deberse a la constitución primaria de la naturaleza humana, a la costumbre o al capricho. Es la fábrica o 
la estructura de la mente humana la que hace que el hombre sea capaz de tales sentimientos. En el caso de la costumbre, hay que pensar que es ella la que nos lleva a asociar la representación de ciertas cosas con la del deleite estético y que éstas son aptas por naturaleza para engendrar en nosotros dicho placer. $Y$ en el del capricho, la asociación es arbitraria. El placer que provoca lo bello y el dolor que produce lo feo son, según Hume, pasiones directas, es decir, que nacen en el alma, de modo inmediato, de la contemplación de un objeto; y calmas, o sea, que no causan una gran agitación sensible. Para que surja el placer, el objeto debe poseer cierta aptitud que se expresa en cierta unidad, coherencia, enlace, homogeneidad y equilibrio de sus partes. Y deben cumplirse condiciones internas, secundarias o reflejas en el sujeto, que constituyen su gusto o sentimiento que se traduce en la evocación de ideas y sentimientos apropiados, en el funcionamiento rápido y natural de las facultades, en la satisfacción y armonización de tendencias y en el movimiento regular de la energía psíquica según sus leyes, de donde se desprende un sentimiento de unidad y libertad profundas (todo lo anterior según la interpretación de $\mathrm{O}$. Brunet). Además del deleite provocado por lo bello, que es, como acabamos de manifestar, calmo, Hume ha considerado otros placeres estéticos que son violentos, como el de lo sublime, caso en el que el objeto nos causa inicialmente desagrado, porque no podemos aprehenderlo o por la incertidumbre que experimenta la imaginación; pero posteriormente el sentimiento inicial es superado, produciéndose entonces un placer noble e intenso. La intensidad de la experiencia de los sublime se debe al contraste entre los sentimientos que la integran, y a la absorción de la pasión secundaria (el dolor) por la dominante (el placer).

Según la concepción general del arte de Hume, éste está formado por una fusión de elementos -datos, préstamos, reemplazos o transformaciones de lo real- organizados en un "sistema de apariencias", que es diferente del "sistema de realidades" que vivimos habitualmente. Esta trasposición de lo real está destinada a satisfacer en el plano de lo imaginario las tendencias naturales de la vida afectiva. El sistema de apariencias guarda conformidad con los principios que gobiernan el funcionamiento de nuestras actividades psíquicas (O. Brunet). A fin de que experimentemos placer con la narración de otra persona, es preciso que le otorguemos algún crédito: de ahí que no sintamos ninguna satisfacción con la conversación de los embusteros y que los poetas - mentirosos por profesión- se esfuercen en otorgar un aire de verdad a sus ficciones (Tratado...). A fin de cuentas, la verdad y la realidad son requisitos para que las ideas entretengan a la imaginación; de este modo el material de la ficción es acogido sin dificultad, causando una profunda impresión en la fantasía y en sus afecciones. Pero además se requiere que el "sistema poético de cosas" esté construido de tal modo que vaya acompañado de una impresión 
de vivacidad que haga creer en lo narrado, y que la imaginación del autor sea muy vigorosa y elocuente.

De acuerdo con Hume, el gusto es indefinible y sólo puede ser determinado por oposición a la razón como la facultad de sentir lo bello o lo feo en el ámbito de la estética; o lo malo y lo bueno, la virtud y el vicio en el campo moral: "los distintos límites y funciones de la razón y el gusto son fáciles de discriminar. La primera transmite el conocimiento de la verdad y la falsedad, el último procura el sentimiento de belleza y fealdad, del vicio y la virtud. La una, descubre los objetos tal como se encuentra realmente en la naturaleza, sin adición o disminución; el otro posee una capacidad productiva que, dando brillo o mancillando todos los objetos con colores prestados del sentimiento interno, produce de algún de modo una nueva creación. La razón es fría y no comprometida y no es motivo para la acción, y sólo dirige los impulsos recibidos del apetito o de la inclinación, mostrándonos los medios de lograr la felicidad y eludir la miseria. El gusto nos causa placer o dolor y por ello constituye la felicidad o la miseria, llega a ser motivo de la acción y es el primer resorte o impulso para el deseo o la volición. Partiendo de circunstancias o relaciones conocidas o supuestas, la primera nos conduce al descubrimiento de lo oculto o desconocido. En cambio, después de que todas las circunstancias y relaciones están ante nosotros, el segundo nos hace sentir, a partir de los efectos del todo, un nuevo sentimiento de desaprobación o aprobación. La norma de la una, que está fundada en la raturaleza de las cosas, es eterna e inflexible, aun para la voluntad del ser supremo; la norma del otro, que nace de la estructura y constitución interna de los animales, deriva en último término de la voluntad del ser supremo, que ha concedido a todo ser su naturaleza peculiar y ha regalado las diferentes clases de órdenes de existencia” (Los principios de la moral). Esta extensa cita muestra que, mientras el gusto era en Hutcheson un órgano pasivo de aprobación o de gozo, en el caso de Hume posee una capacidad genuinamente creadora (O. Brunet) y constituye una función sintética de la imaginación. Por otro lado, como suscita placer y dolor, es una principio de acción. Sus normas no se fundan en la naturaleza de los objetos, sino en la del sujeto por designio divino.

El gusto se puede cultivar produciendo una delicadeza que aumenta nuestra sensibilidad para las pasiones tiernas y agradables y la disminuye para las rudas y violentas. Dos razones obran para ello. La primera es que el estudio de la belleza en la poesía, elocuencia, música o pintura nos concede una elegancia de sentimientos ajenos al resto de la humanidad. Y la segunda es que la delicadeza del gusto es propicia para el amor y la amistad, siempre que limitemos nuestra elécción a poca gente y se nos convierta en indiferente la conversación de la mayoría de los hombres.

Hume fundamenta el dicho popular según el cual es vano disputar sobre el gusto: ya que la belleza no consiste en una propiedad real que se encuentre 
en las cosas, sino en el placer calmo que experimentamos ante la forma de los objetos, el gusto de cada individuo tendrá su propia validez. Y, sin embargo, sostiene nuestro autor, hay ciertamente una especie de sentido común que se opone a este principio y que sirve para modificarlo y restringirlo. Sucede que nadie afirmaría una igualdad de genio y elegancia entre Ogilby y Milton o entre Bunyan y Addison, y que si esto ocurriera nadie prestaría atención a este gusto particular y señalaríamos que este sentimiento es absurdo y ridículo. Pues bien, hay reglas del arte, pero no han sido forjadas a priori ni son el resultado de conclusiones abstractas del entendimiento, sino que surgen de la experiencia. Estas reglas se establecen observando la naturaleza humana y en forma empírica, lo que no quiere decir que el sentimiento se pueda conformar siempre a ellas. Para aplicar las normas del gusto es necesario que se den siempre tres circunstancias: una perfecta serenidad de la mente, la concentración del pensar y la atención debida al objeto. Oscura es la relación que la naturaleza ha instituido entre la forma de las cosas y el sentimiento, sostiene Hume, y sin embargo se puede discernir de la admiración duradera que ha sobrevivido a todos los caprichos de la moda y a todos los malentendidos de la ignorancia y de la envidia. La autoridad o el prejuicio pueden dar una vigencia temporal a una autor, pero su reputación no permanecerá. En cambio, un genio genuino será a la larga reconocido y todos los cambios de clima, gobierno, religión y lenguaje no podrán mellar su gloria.

Los principios del gusto son universales y casi los mismos en todos los hombres. No obstante, pocos son quienes, en opinión de Hume, están calificados para juzgar las obras de arte y establecer sus propios sentimientos como norma de belleza, porque para ello se requiere: 1) que los órganos de las sensaciones internas se encuentran en perfectas condiciones; 2) que el crítico posea delicadeza de gusto; 3) que se vea ayudado por la práctica; 4) que haya efectuado comparaciones apropiadas a fin de no conceder su admiración a bellezas frívolas; 5) que se haya liberado de sus prejuicios; 6) que posea una entendimiento que le permita discriminar las bellezas del diseño y del razonamiento que son las más altas y excelentes. La generalidad de los hombres juzga faltándole uno o más de estos requisitos, "y es por ello que se observa que es una carácter tan raro el de un juez genuino en el campo de la bellas artes, aun en la épocas más cultivadas: tan sólo un sentido fuerte unido a una sentimiento delicado, incrementado pc:- la práctica, perfeccionado por la comparación y liberado de todos los prejuicios, puede conceder a los críticos el título de tener esta carácter valioso; y el veredicto conjunto de éstos, dondequiera que se los encuentre, constituye la norma verdadera del gusto y de la belleza" ("De la norma del gusto").

Pero, ¿cómo se puede encontrar estos críticos?, ¿qué rasgos los caracterizan?, ¿cómo distinguirlos de quienes sólo elevan la pretensión de ser jueces genuinos sin serlo en verdad? Éstas son preguntas difíciles y nos confunden, 
reconoce Hume. Por otro lado pareciera que es mucho más sencillo hallar criterios en el campo de las ciencias que en el del arte. Mas en realidad no es así: mientras las teorías científicas cambian, permanece el reconocimiento otorgado a las grandes obras literarias y científicas. Los hombres de gusto delicado son raros, pero son fáciles de distinguir en sociedad por el carácter sano de su entendimiento y la superioridad de sus facultades sobre el resto del género humano. Adquieren un gran ascendiente, y así sus juicios reciben una aprobación que por lo general se convierte en predominante.

No obstante, pese a todos los esfuerzos para fijar una norma del gusto, hay dos fuentes de variación de la misma que, si no son suficientes para confundir la belleza y la fealdad en su límites, producen diferencias en los grados de nuestra aprobación o desaprobación. Se trata de los diferentes humores de los hombres particulares, que dependen de la estructura interna o de su situación externa; y de las costumbres y opiniones particulares de cada época y país.

\section{William Hogarth}

Nació en 1697 y falleció en 1764. Fue un famoso grabador que llegó a ser nombrado pintor del rey Jorge II. Es uno de los artistas más típicamente ingleses de su tiempo, con una gran veta popular. Su tratado The Analysis of Beauty. Written with a View of Fixing the Fluctuating IDEAS of TASTE (Londres, 1753) es el que lo ha hecho ingresar a la historia de la estética.

El libro de Hogarth comprende un prefacio, una introducción y diecisiete capítulos. En el prefacio el autor manifiesta que el título de su obra puede provocar expectación y duda; porque, aunque todos los hombres dan testimonio de la belleza, se ha renunciado a investigarla debido a que se juzga que se trata de un estudio extraordinariamente difícil e infecundo. $\mathrm{Y}$, sin embargo, los pintores del pasado habrían poseído la clave de la belleza, como Miguel Ángel, y también los artistas de la Antigüedad. Esta clave no es otra cosa que la linea serpentina que conjuga en sí la unidad en la variedad, fórmula en la que se ha visto desde hace mucho tiempo la definición misma de la belleza. En su The Analysis of Beauty Hogarth quiere fijar las ideas fluctuantes sobre el gusto, con la revelación de los secretos de la línea serpertina.

En la introducción, el autor comienza indicando que, para captar la verdad y los principios que expone, es necesario liberarse de los prejuicios que nuestra propia práctica o el aprendizaje con los otros han suscitado en nosotros. Estos prejuicios nos mantienen atados a las imitaciones, alejándonos de la naturaleza, nos fijan a las maneras y nos impide una visión libre. Hogarth propone un método para dibujar y componer. Para ello es preciso examinar la variedad de líneas que sirven para hacer surgir las ideas de los cuerpos en la mente, líneas a las que ve como si estuvieran dibujadas en las superficies interior y exterior de los cuerpos sólidos y opacos. De ahí que la introducción 
lleve por tírulo "Uso y ventaja de considerar a los objetos sólidos como sólo conchas delgadas compuestas de líneas semejantes a la cáscara de una cebolla." Pensando los objetos como conchas, los podemos concebir mucho más fácilmente —desde el punto de vista gráfico-, ya que la imaginación ingresa entonces naturalmente al espacio vacante dentro del interior de la concha y ve desde ahí la forma entera.

En los seis primeros capítulos de su tratado, Hogarth establece cuáles son los principios generales de la composición plástica de los objetos que más pueden complacer y entretener al ojo, confiriéndole belleza y gracia. $\mathrm{Y}$ es que mientras los tratados clásicos sobre pintura introducían un orden en este arte, dividiéndolo en partes sobre la base de un modelo retórico -invención, proporción, color, acción y composición-, nuestro autor sigue un esquema clasificatorio típicamente plástico, incorporando, además, algunos tópicos prestados de la estética ( $R$. Woodfield). Los principios a los que Hogarth se refiere son: 1) la conveniencia de las partes al designio para el cual la cosa ha sido formada; 2) la variedad compuesta; 3 ) la uniformidad, regularidad o simetría; 4) la simplicidad; 5) la intricación de las líneas que conducen al ojo a una caza desenfrenada para captarlas; y 6) la cantidad o sublimidad de los objetos. Estos principios se reducen en realidad a tres: la conveniencia, la variedad y la cantidad, ya que los otros tres están incluidos bajo el segundo: la uniformidad y simplicidad son complementarios de la variedad, y la intricación es un modo suyo.

A continuación, Hogarth trata de la forma. Primero se refiere a la superficie (primera idea de la forma: de las clases de líneas y de cómo componer las formas placenteras de los objetos), y después al volumen y solidez generales y particulares de los objetos (segunda idea de la forma: de la proporción). Distingue las siguientes clases de formas: 1) objetos compuestos de líneas sólo rectas (por ejemplo el cubo), de líneas sólo curvas (el círculo) o de ambas clases de líneas (como los cilindros); 2) objetos compuestos de líneas rectas y curvas (los capiteles de las columnas); 3 ) objetos compuestos de todas las líneas anteriores y de la línea ondulada, que es más productora de belleza que las líneas anteriores, por lo que debe ser denominada "línea de la belleza" (que se encuentra, por ejemplo, en las flores); 4) objetos compuestos de todas las líneas anteriores más la línea serpentina, que tiene el poder de añadir gracia a la belleza (como en la forma humana). Las formas menos graciosas son las que menos líneas rectas tienen -y varian sólo en el largo. Más ornamentales son las líneas curvas - que agregan al largo la curvatura. Poseen mayor vivacidad las líneas onduladas -que añaden la variación de dos curvas contrastantes. Y la línea serpentina que se ondula y desarrolla al mismo tiempo, "conduce al ojo de una manera placentera a lo largo de la continuidad de la variedad". El arte de componer bien es el arte de variar bien: hay que elegir una variedad de líneas apropiadas para los aspectos y dimensiones de las for- 
mas; hay que variar las situaciones de unas formas con respecto a las otras y también los contenidos o espacios que se incluirán en el interior de las líneas. Aunque, si son correctamente aplicadas, todas las líneas onduladas y serpentinas son ornamentales, hay líneas precisas de la belleza y de la gracia. La línea ondulada no debe ser tan curvada que se convierta en tosca y desmañada, ni tan recta que se transforme en insignificante y pobre. Y por su parte, la línea serpentina no debe ser ni demasiado enrollada ni en exceso menguante. Ambas deben ser juiciosamente aplicadas y combinadas con las otras líneas según los seis principios generales de la composición ya expuestos.

La segunda idea de la forma, referida al volumen y solidez generales y particulares, tiene que ver con el contenido de las superficies y además con lo que las ha generado, así como con ciertas cantidades dadas y dimensiones de partes, con objeto de incluir alguna sustancia o de efectuar un movimiento, un incremento, un reposo y todo lo usual en lo seres vivientes. "Lo que $[. .$.$] nos$ acercará a una concepción tolerable de la palabra proponción.” Ésta no es para Hogarth "la simetría y armonía juntas de las partes con respecto al todo", concepción tradicional a la que él critica por su vaguedad, sino la adecuación de un cierto volumen o movimiento a un cierto propósito. Por consiguiente, la proporción concierne más a lo que percibe la mente que a lo que capta la vista. Un primer método que Hogarth propone para establecer la dimensión adecuada de un objeto es prescindir de su contenido e imaginar las líneas que lo rodean, tal como postuló anteriormente: así adquiriremos la idea de qué largos en relación con qué anchos constituyen las proporciones más elegibles en general. Un segundo método se sirúa en el sendero familiar de la observación común y apela a nuestro sentimiento habitual $\longrightarrow$ sensación conjunta- de la figura y el movimiento para tratar de determinar la dimensión más apropiada del caso. La palabra clave es aquí el carácter del objeto que se trata de representar: su adecuación a algunas circunstancias o causas de su apariencia.

Posteriomente, Hogarth se refiere a la luz, sombras y colores y a su composición. Los colores los concibe como sombras matizadas, tratándolos conjuntamente con las sombras comunes. Entre éstas distingue las primeras tintas: los contrastes de unos colores con otros en la superficie de los objetos, y las sombras retrocedentes, o sea, las ocasionadas por la privación gradual de la luz o por el lápiz del artista o por la naturaleza que opera como un lápiz. Esta última clase de sombras se subdivide en cuatro especies -en correspondencia con las clases de líneas. Los principios que norman la composición placentera de la luz y de las sombras - y de los colores- son los de la oposición, ancho y simplicidad, que producen una percepción justa y distinta de los objetos que están ante nuestros ojos. Los seis principios generales de la composición de las formas se aplican también para lograr la belleza del colorido de la figura humana, en especial los de la variedad, intricación y simplicidad. 
Finalmente, Hogarth se ocupa de la faz humana, la actitud y la acción. En su opinión, la línea serpentina tiene una gran fuerza en el rostro, el cual constituye un índice de la mente. A esta observaciones agrega otras sobre la importancia de las demás líneas para el carácter y la expresión y las diferentes edades del hombre. Termina formulando algunas apreciaciones sobre la actitud y la acción humanas.

\section{Alexander Gerard}

Nació el 22 de febrero de 1728 en Aberdeenshire y falleció el mismo día de su cumpleaños en 1795 en Aberdeen. Fue predicador de la iglesia de Escocia, profesor de filosofia en varios colleges, perteneció a la Select Society de Edimburgo y a la Philosophical Society fundada por Thomas Reid en 1758. Recibió la influencia de Shaftesbury, Hutcheson y Baillie, e influyó a su vez en Hogh Blair. De entre sus numerosas publicaciones dos sobresalen para la historia de la estética: $A n$ Essay on Taste (Edimburgo, 1759) y $A n$ Essay on Genius (Edimburgo, 1774).

En la tercera edición definitiva de 1780, el Essay on Taste comprende una introducción y cuatro partes -que tratan de: 1) los principios del gusto; 2) su formación; 3) su campo e importancia, y 4) la norma de gusto. En la introducción Gerard comienza aseverando que un gusto refinado no es por completo ni un regalo de la naturaleza ni el efecto del arte. Procedería de ciertos poderes naturales de la mente que llegan a su perfección cuando son cultivados. "El gusto consiste principalmente en el aumento de aquellos principios que son comúnmente denominados poderes de la imaginación y a los que los filósofos modernos [F. Hutcheson] consideran sentidos internos o reflejos, los cuales nos proporcionan percepciones más finas y delicadas que las que - pueden ser referidas a nuestros órganos externos. Estos sentidos son reducibles a los siguientes principios: los sentidos de la novedad, de la sublimidad, de la belleza, de lasinitación, de la armonía, del ridículo y de la virtud.” Estos sentidos son subsecuentes a los externos, porque suponen su ejercicio (como la percepción de la armonía implica escuchar ciertos sonidos), y son reflejos, porque para su ejercicio la mente reflexiona advirtiendo la circunstancia y modo de los objetos que percibe (para que "experimentemos" la novedad de una cosa es preciso que reflexionemos sobre ella).

La primera parte de la obra se denomina "El gusto reducido a sus principios simples", y comprende siete secciones que tratan de: 1) "El sentido o gusto de la novedad"; 2) "El sentido o gusto de la grandeza o sublimidad"; 3) "El sentido o gusto de la belleza" (que puede ser: a) de la uniformidad, variedad y proporción, b) de la utilidad o conveniencia, c) de los colores); 4) ${ }^{\circ} \mathrm{El}$ sentido o gusto de la imitación"; 5) "El sentido o gusto de la armonía"; 6) "El sentido o gusto del ridículo"; 7) “El sentido o gusto de la virtud" —que en realidad es 
un sentido moral, pero que extiende su influencia a las obras más considera-. bles del arte y del genio. Esta parte contiene un compendio de los puntos de vista procedentes de la tradición y de los antecesores de Gerard, quien los resume de esta forma: "Existen cualidades determinadas y estables de las cosas, independientes del humor y capricho [individuales] que son adecuadas para operar sobre los principios mentales comunes a todos los hombres; y al actuar sobre ellos producen con naturalidad los sentimientos de gusto en todas sus formas. Si en algún caso particular prueban no ser efectivas, hay que atribuir este hecho a alguna debilidad o desorden en la persona que permanece intocada al mostrarse estas cualidades ante los ojos. Con pocas excepciones, los hombres resultan afectados por las cualidades que hemos investigado; no obstante, estas cualidades son, sin excepción alguna, constituyentes de la excelencia o corrupción de distintas especies."

La segunda parte del libro lleva por título "La formación del gusto por la unión e incremento de sus principios simples”. Para formar el gusto es necesario, según Gerard, que los sentidos internos se combinen, recibiendo la asistencia de la delicadeza de la pasión - que hace que las obras de genio cumplan su efecto pleno e inspiren un placer complejo. Pero, además, es preciso que colabore con ellos el juicio, midiendo la amplitud de las cosas, exhibiendo las bellezas y excelencias de la naturaleza, destacando la construcción inteligente de los objetos, descubriendo sus cualidades demasiados escondidas, investigando las leyes y causas de las obras de la naturaleza y contrastando éstas con las obras de arte; así proporciona materiales a partir de los cuales la fantasía puede producir ideas y formar combinaciones que habrán de afectar fuertemente el gusto mental. De acuerdo con Gerard, para formar el gusto es necesario cultivar tanto los sentidos - externos y, sobre todo, internoscomo el juicio. El gusto posee una naturaleza progresiva: comienza rudo, poco aguzado y limitado, se educa gradualmente y sólo en forma paulatina alcanza su mejor condición. "La bondad del gusto se halla en su madurez y perfección. Consiste en ciertas excelencias de nuestros poderes de juicio e imaginación combinados. Pueden ser reducidas a cuatro: sensibilidad, refinamiento, corrección y la proporcion o ajuste comparativo de sus principios separados. Todas estas excelencias deben estar unidas en algún grado, con el fin de formar un gusto verdadero." El buen gusto no debe serlo sólo cultivado, sino además juiciosamente aplicado. Gerard se refiere también a la sensibilidad, refinamiento y corrección del gusto y a la proporción adecuada de sus principios. En su opinión, Longino habría sobresalido sobre todo por su sensibilidad, Dionisio de Halicarnaso por su refinamiento, Aristóteles por su correción y amplitud y Quintiliano por poseer juntas todas estas cualidades.

"La Provincia e importancia del gusto" es el título de la tercera parte. Los fenómenos del gusto proceden ya sea de las leyes generales de la sensación o de ciertas operaciones de la imaginación. Por una parte, podemos distinguir 
en la experiencia del gusto, como ya hemos dicho, las percepciones externas y, como consecuencia de ellas, las percepciones internas. Estas últimas son simples en los sentimientos e independientes en la volición: no podemos ni provocarlas, ni cancelarlas, ni ocultarlas. Es decir, el sentimiento del gusto es compuesto en sus principios - las percepciones externas e internas-, pero es simple en sí mismo. Es una clase de sensación sometida a las leyes de las sensaciones, entre otras a la de adaptarse a los objetos, experimentar una emoción y ser colocada en una estructura análoga a la del sujeto que la provoca (como encontrar una dificultad produce la emoción de realizar un ejercicio agradable de energía para resolverla). Por otra parte, el fenómeno del gusto surge de las operaciones de la imaginación, en especial de sus asociaciones, de la comparación de ideas, de su combinación y del acto por el cual las confunde con las sensaciones. Por cierto, esto no significa que esta experiencia sea sólo fantástica o imaginaria. El gusto está unido con el genio, precisamente porque los dos tienen su fuente en la imaginación. Para poder hacer crítica literaria es necesario tener gusto, pero además poseer un genio filosófico, ya que es necesario elevarse de los objetos poéticos a las leyes que los gobiernan y compararlas con los principios de la naturaleza humana para tratar de establecer por qué ciertas cualidades provocan placer. "Si falta el gusto nuestras conclusiones serán defectuosas, erróneas o precarias; si el genio filosófico está ausente, nuestras observaciones serán triviales, superficiales, inconexas y complicadas con grandes particularidades. Tanto en la ciencia como en el arte empleamos la razón y el gusto; pero mientras en aquélla la primera facultad es el juez último y la segunda es un sólo auxiliar, en cuestiones artísticas el gusto es el juez supremo y la razón únicamente su ministro. El gusto tiene efectos inmediatos y remotos: los primeros son placeres inmediatos, inocentes, elegantes y nobles; los efectos remotos son la influencia sobre las pasiones y el carácter.”

La cuarta parte del libro se refiere a la norma del gusto. Según Gerard las variaciones en el gusto han llevado a afirmar que no hay a este respecto criterio alguno. Esta posición omite ver que en el gusto participan no sólo el sentimiento, en relación con el cual no puede fijarse en efecto norma alguna, sino además el juicio, que sí permite establecer un criterio. Esto no significa llevar a reconciliar y a hacer coincidir todos los gustos, sino sólo que se puede mostrar cuál es el mejor gusto entre varios gustos diversos. Y es que Gerard cree que es posible hacer que una persona cambie sus sentimientos sobre un objeto estético y su juicio al respecto, siempre que esté dispuesta a ello —en otro caso la convicción más firme se estrellará contra una sensación pervertida. La norma de gusto no es algo externo, que pueda ser sometido a medida, sino interno: tiene que derivarse de las cualidades generales del mismo gusto o de los principios generales de la naturaleza humana. Gerard cree que así como los experimentos y observaciones permiten formular las leyes que regulan los fenómenos de la naturaleza, el examen de lo que place y disgusta 
posibilita formular las leyes que norman las obras de la imaginación; y si ellas se oponen a los sentimientos no pervertidos de un individuo es que se ha cometido algún error de inducción. En primer lugar, hay que abandonar la admiración indiscriminada; luego se debe examinar lo que place y disgusta y después tratar de determinar qué cualidades son las que placen o disgustan (la variedad, la amplitud, la adecuación o una finalidad y sus opuestos). Finalmente, hay que poner en conexión estas cualidades con los principios de la naturaleza humana; las diferencias individuales en las reacciones ante un mismo principio pueden salvarse recurriendo a la experiencia del género humano. La investigación de las causas inmediatas o próximas de los placeres del gusto y un análisis de éstos que conduzca a los principios últimos de la mente ha de llevar, en opinión de Gerard, a un sistema de reglas que coincida con los sentimientos naturales y no pervertidos de los individuos. Una cualidad estética será tanto más valiosa cuando gratifica a un mayor número de principios a la vez (así se debe reconocer que la belleza supera a la novedad, porque gratifica a más principios). Al establecer reglas estéticas generales de este modo, el hombre de gusto no necesitará esperar la aprobación general de las obras de arte para pronunciarse sobre éstas, sino que podrá predecir que el juicio de los otros habrá de coincidir con el suyo propio.

El An Essay on Genius consta de una introducción y de tres partes. En la primera Gerard subraya las dificultades que acompañan a las investigación de los principios de la naturaleza humana debidas a que los fenómenos de la mente no tienen una firmeza de existencia tan grande como las cualidades de los cuerpos y porque es imposible hacer o repetir con facilidad experimentos sobre el entendimiento orientados intencionalmente. La dificultad de esta investigación ha conducido, de acuerdo con el autor, a que hasta ahora no se haya examinado con cuidado el genio, el cual él quiere estudiar.

La primera parte del Essay... trata de la naturaleza del genio. El genio es la facultad de invención con ayuda de la cual el hombre está calificado para hacer nuevos descubrimientos en la ciencia o para producir obras originales de arte. De los cuatro poderes intelectuales del hombre - sensación, memoria, juicio e imaginación- el genio pertenece sin duda a este último, asistido por las otras facultades; pues la imaginación librada a sí misma desemboca en el capricho y en la extravagancia salvajes. El sentido y la memoria procuran a la imaginación sus elementos, y el juicio corrige y regula sus sugestiones. El genio surge de la imaginación gracias a las conexiones nuevas e inesperadas que ésta establece. Al efectuar asociaciones la imaginación está lejos de ser caprichosa o irregular y observa las más de las veces reglas generales y establecidas. La imaginación del genio debe ser comprensiva of fértil y regular. $\mathrm{Si}$ la fertilidad falta, la imaginación será fluida pero quedará confinada por lazos estrechos; y si es la regularidad la que está ausente, la imaginación exuberante se perderá en lo agreste de su propia invención. El genio implica asimismo 
que la imaginación está en actividad, que no sólo acumule materiales y que sea acompañada por el entusiasmo. Tanto en el caso de las ciencias como en el de las artes, es imprescindible que el juicio asista a la imaginación. Esto es evidente en el primer caso, pero también es cierto en el segundo: el juicio ayuda a controlar la exhuberancia de la fantasía y a hacerla regular. También la memoria colabora con el genio: con frecuencia es conducido a sus invenciones por una cadena de ideas sugerida por una cadena semejante que la memoria retiene y es solamente el recuerdo de esta última la que capacita al juicio para determinar la justeza de la primera.

La parte segunda del libro trata "De las fuentes generales de las variedades del genio", y en ella estudia Gerard las diferencias introducidas en éste por los cambios en las facultades determinantes del genio -imaginación, memoria y juicio. En la parte tercera de la obra el autor va a ocuparse de las clases de genio, pero adopta el punto de vista de la naturaleza del objeto para el que se emplea o del fin perseguido. De acuerdo con este criterio existen dos clases de genios: en las ciencias, donde se busca la verdad, y en las artes, en las que se indaga por la belleza; ambos son diferentes, pero por distintas razones. Las diferencias aumentan por el distinto modo en que en cada caso se combinan la imaginación, la memoria y el juicio hasta llegar casi a una oposición entre estos dos tipos de genialidad. Y, sin embargo, esto no autoriza a decir que el genio en las ciencias sea incompatible con el genio en las artes, ya que la historia prueba lo contrario; pero sí que si una persona une las dos clases de genialidad sólo destacará en una de ellas. En algunas ocasiones la unión será más aparente que real: el poder de invención en un ámbito sólo estará acompañado por la mera capacidad en el otro.

\section{Edmund Burke}

Nació en Dublín el 12 de enero de 1729 y falleció en Beaconsfield el 8 de julio de 1797. Es conocido sobre todo como orador y como hombre político y por sus Reflections on the Revolution in France (Londres, 1790). A la filosofia y a la historia de la estética, interesa más bien por su libro juvenil $A$ Philosophical Enquiry into the Origin of our Ideas of the Sublime and the Beautiful (Londres, 1757).

La Enquiry... se divide en una introducción o discurso preliminar y en cinco partes que tratan de las pasiones de lo sublime y de lo bello (I), de lo sublime (II), de la belleza (III), de la causa eficiente de la sublimidad y la belleza (IV) y de las palabras (V). En la introducción, que trata del gusto, se ha querido ver una contestación del ensayo de Hume "De la norma del gusto". Burke entiende por gusto "aquella facultad o facultades de la mente que son afectadas por la obras de la imaginación y las bellas artes, o que forman juicio sobre ellas", y piensa que es posible determinar sus principios. En 
la acepción más general de la palabra "gusto", ésta no es una idea simple sino compuesta, en parte por los placeres primarios del sentido, en parte por los placeres secundarios de la imaginación y en parte por las conclusiones que la razón deduce de ellos acerca de las varias relaciones y también acerca de las pasiones, costumbres y acciones humanas. Pese a que los principios del gusto son uniformes en todo el género humano, el grado en que prevalecen es distinto debido a que la sensibilidad y el juicio varían en los distintos individuos. De la falta de la primera nace el defecto del gusto, de la debilidad del segundo el que sea irregular y malo. Burke critica a Shaftesbury y a Hutcheson por hacer del gusto una facultad del ánimo separada y distinta del juicio y de la imaginación. En opinión suya, aunque en lo referente a la imaginación y a las pasiones se consulta muy poco a la razón, "en lo tocante a la disposición, al decoro, a la congruencia, en una palabra siempre que el mejor gusto se diferencia del peor, estoy convencido de que el entendimiento es el que obra y nada más; y su operación está muy lejos de ser repentina, o si lo es, las más de las veces está lejos de ser recta". En verdad, el gusto se mejora al mejorar el juicio extendiendo los conocimientos mediante una constante atención al objeto y al frecuente ejercicio.

En la primera parte de la Enquiry Burke trata de las pasiones de lo sublime y de lo bello. Sostiene que lo sublime está asociado con las pasiones ligadas a la propia conservación, que versan sobre la pena y el peligro, sin que nos hallemos actualmente en tales circunstancias; y lo bello tiene que ver con las pasiones que tienen como causa final a la sociedad, que residen en el amor y en las emociones acompañantes, pero sin mezcla de placer - lo que las diferencia de las pasiones sexuales que se experimentan en sociedad, que conciemen asimismo al amor, pero acompañado de placer. Por consiguiente, lo sublime es aquello que es apropiado para suscitar las ideas de pena y de peligro; y lo bello la cualidad que tienen los seres humanos y animales para excitar en nosotros un sentimiento de alegría y deleite con sólo mirarlos.

A continuación pasa el autor a tratar con más detalle de lo sublime en la segunda parte del libro. Lo sublime causa en nosotros, según Burke, la pasión del asombro: aquel estado del alma en que todos los movimientos se suspenden con un cierto grado de horror. Los efectos inferiores de lo sublime son la admiración, la reverencia y el respeto. La principal causa de la sublimidad es el miedo (sea producido por las grandes dimensiones del "objeto" contemplado o por otra razón), y otras causas suplementarias son la oscuridad, el poder, la privación, la vastedad, la informidad, la sucesión y la uniformidad, la magnitud de los edificios, la infinitud en los objetos agradables, la dificultad, la magnificencia, la luz en general y en los edificios, el color, el sonido y el estruendo, la prontitud, la intermisión, los gritos de los animales, el olor y el sabor, el tacto y la pena. Según Samuel H. Monk, ya antes de Burke se había sostenido que la idea que lo sublime suscita es completamente irracio- 
nal; lo nuevo en la Enquiry... sería el ánimo de otorgar una base pseudocientífica a esta reacción. Por otra parte, ninguna de las causas que según el autor provocan la experiencia de lo sublime se encontraría en el arte neoclásico -con excepción del poder-; esto lleva a legitimar y a revalorizar los afectos provocados por el arte no clásico. Es además destacable que Burke rechace la claridad, uno de los criterios de las ideas verdaderas según Descartes, como una causa de lo sublime. Y, finalmente, el gran aporte del autor a la estética consiste en la idea de la magnificencia como causa de la sublimidad, la idea de que el aparente desorden de las cosas aumenta la grandiosidad (W. Folkierski). Es cierto, ya antes Boileau había dicho a propósito de la oda que en ella un bello desorden constituye un efecto estético, pero no elogiando el desorden en sí, sino en nombre del orden; en cambio, en Burke es un "desorden magnífico" el que engendra una apariencia de infinidad.

La tercera parte del libro se refiere detalladamente a la belleza. Aunque quien primero opuso tajantemente lo bello y lo sublime fue Isaac Hawkins Browne en su An Essay on Design and Beauty (1739), es a Burke a quien corresponde el mérito de haber despejado la confusión que aún subsistía hacia 1757 en el uso de ambos términos (S. Monk); lo que era uno de los propósitos declarados de la Enquiry. .., como lo manifiesta su prefacio. El autor limita su definición de la belleza a las cosas meramente sensibles: las cualidades de los cuerpos que nos causan amor o alguna pasión semejante con sólo verlos. Esta determinación le permite a Burke evitar las opiniones tradicionales, según las cuales la bellèza consistía en la proporción, la conveniencia o en la perfección. La belleza no consiste en la proporción: ésta tiene que ver con las cosas mensurables y la belleza no es una idea perteneciente al orden de lo mensurable o que tenga que ver con el cálculo y la geometría. Ni en la naturaleza ni en el hombre puede considerarse que ciertas proporciones sean la causa de la belleza. El delgado tallo de una rosa no conviene con su abultada cabeza, el cuello de un cisne es demasiado largo para su cuerpo; y, sin embargo, se suele considerar bellos a las rosas y a los cisnes. Por lo demás, ninguna especie está ceñida a medidas ciertas y tampoco el género humano. La “divina proporción” del hombre es sólo una analogía formada para acreditar algunas obras de arte. La naturaleza no puede someterse ni a reglas ni a trabas. Lo que verdaderamente se opone a la belleza no es la desproporción sino la fealdad.

Tampoco es correcta la concepción según la cual la conveniencia es la causa de la belleza. Por conveniencia se entiende la conformidad (suitableness) de los medios para ciertos fines, sea en el caso de los objetos artificiales como en el de los seres naturales. Pero esta idea de la belleża es errónea, según Burke, porque si fuera cierta habría que declarar bellos al hocico de un cerdo que se ajusta perfectamente al trabajo que debe realizar hozando la basura, la bolsa de un pelícano, la trompa de un elefante o la fuerza masculiṇa. “Yo me imagino”, 
escribe el autor, "que la causa de esta confusión proviene de que percibimos frecuentemente que las partes del cuerpo humano y de los otros animales son a un mismo tiempo bellas y muy bien acomodadas a sus fines; y nos engañamos por un sofisma, el cual hace que tomemos por causa lo que sólo es un comitante”. Ahora bien, sostener que la proporción y la conveniencia no constituyen las causas de la belleza en el reino vegetal, animal y humano, no significa defender que de nada sirven o que deben ser desatendidas. Por el contrario, "las obras de arte son la esfera propia de su poder, y en ellas es donde surten todo su efecto", que es el de la aprobación o la aquiescencia del entendimiento, pero no el amor u otra pasión de esta especie, ya que "el efecto de la belleza precede a todo conocimiento del uso de las cosas bellas".

Finalmente, tampoco la perfección es causa de la belleza, ni en el caso de lo físico -como lo saben las mujeres que introducen defectos en su modo de comportarse a fin de resultar más atractivas-, ni en el de lo anímico - ya que lo perfecto despierta antes temor que amor, como sucede con la fortaleza, la justicia, la sabiduría.

Luego de esta determinación negativa de la belleza, pasa Burke a la positiva: "La belleza, en su mayor parte, es alguna cualidad en los cuerpos que actúa en forma mecánica sobre la mente humana mediante la intervención de los sentidos." En cuanto meramente sensibles, estas cualidades son: 1) el que los cuerpos bellos sean comparativamente pequeños; 2 ) el que sean tersos; 3 ) el que varíe la dirección de sus partes; 4) el que sus partes no sean angulares, sino que se pierdan las unas en las otras; 5 ) el que sean de estructura delicada sin ninguna apariencia remarcable de fuerza; 6) el que sus colores sean claros y brillantes, sin llegar a ser en exceso vivos y deslumbrantes; 7) el que si contuvieran algún color deslumbrante, dicho color estaría variado con otros. A estas propiedades se agregan algunas otras: la fisonomía en el caso de la belleza del género humano; los ojos en cuanto a la hermosura de los animales en general; la gracia - idea que pertenece a la postura y al movimiento-, la elegancia y especiosidad de los cuerpos. Todas las cualidades mencionadas son percibidas por la vista, pero pueden aplicarse también en alguna medida al oído, al gusto y al olfato. La belleza del tacto consiste en la impresión agradable que algunos cuerpos nos producen por la leve resistencia que nos oponen. También a través del oído podemos recibir una impresión suave y delicada; pero hay que decir que la belleza de la música se aproxima más a una especie de melancolía que a la alegría y festividad.

Existe un contraste notable entre lo bello y lo sublime: los objetos sublimes son grandes, los bellos pequeños; los primeros son ásperos y negligentes, los segundos lisos y pulidos; en aquéllos puede haber líneas rectas, en éstos no; lo grande debe ser opaco y oscuro, lo bello no ha de serlo; lo sublime tiene que ser sólido y aun pesado; lo hermoso leve y delicado. "A la verdad son ideas de muy diversa naturaleza por fundarse la una en la pena y la otra en el placer; y 
aunque después no convengan en algo con la naturaleza directa de sus causas, éstas mantienen sin embargo una constante y perpetua distinción, que nunca debe olvidar el que tenga necesidad de mover las pasiones.” No obstante lo bello y lo sublime pueden hallarse reunidos en un objeto y mezclarse, pero en este último caso sus virtudes no serán tan eficaces.

En la cuarta parte del libro, Burke se ocupa de la causa eficiente de la sublimidad y de la belleza. No pretende explicar por qué ciertas afecciones del cuerpo producen tal emoción distinta del ánimo, sino cuáles afecciones del ánimo producen ciertas emociones del cuerpo y cuáles sensaciones y cualidades del cuerpo pueden producir ciertas pasiones determinadas del ánimo y no otras. Burke está de acuerdo en aplicar los principios de la asociación, pero le parece absurdo sostener que todas las cosas nos afectan por asociación solamente; en el caso de nuestras pasiones hay que hallar sus causas en las propiedades naturales de las cosas. De acuerdo con el autor, el temor y el dolor muestran los mismos efectos sobre los hombres: contracción muscular y tensión nerviosa. De allí que todo lo que es a propósito para producir una tensión o contracción semejantes, produzca una pasión similar al temor y sea por consiguiente un principio de sublimidad, aunque no tenga conexión alguna con la idea del peligro. ¿Cómo es que lo sublime provoca deleite (su opuesto)? La respuesta es: "si el dolor no llega a ser vehemente y el temor no se refiere a la destrucción actual de la persona, como estas emociones desembarazan las partes - sean finas o toscas - de un estorbo peligroso y molesto, son capaces de producir deleite: no placer, sino una especie de horror deleitoso, cierto género de tranquilidad con un tinte de horror, la cual, como pertenece a la propia conservación, es una de las pasiones más fuertes: su objeto es lo sublime. Llamo asombro al sumo grado de ella; los grados inferiores los llama miedo reverencial, reverencia y respeto." Todo lo que sea capaz de provocar una tensión muscular es, por consiguiente, una causa virtual de lo sublime: en el caso de la vista los objetos de grandes dimensiones, la vastedad sin unidad, la secuencia sucesiva de partes uniformes, la negrura inmoderada; en el caso del oído la sucesión de sonidos fuertes, las vibraciones desemejantes, entre otros casos.

La belleza obra relajando todas las partes del cuerpo, sostiene Burke, y es este estado de relajamiento el que produce la pasión llamada amor: “así como un objeto bello presentado al sentido produce en el ánimo la pasión del amor, causando cierta relajación en el cuerpo; así también cuando por algún motivo tiene la pasión su primer origen en el ánimo, resultará con igual certeza alguna relajación en los órganos externos, en grado proporcionado a la causa de ella". Todo lo capaz de producir un estado de relajamiento corporal será, por lo tanto, una causa virtual de la belleza: la lisura, la dulzura, la variación, la pequeñez, el color. 
La última parte de la Enquiry... se refiere a "Las palabras”. Según Burke: "las palabras nos mueven de muy diferente modo que los objetos naturales o la pintura o la arquitectura; sin embargo, ellas excitan las ideas de belleza o de sublimidad tan bien como cualquiera de estas cosas, y algunas veces mucho más"; de allí que indague de qué modo causan las palabras las emociones. Los efectos que los vocablos producen en nosotros son tres: la percepción del sonido, la representación de la cosa significada y el afecto del alma producida por uno de los dos antecedentes o por ambos. Conforme a Burke, la poesía suscitaría sus efectos no debido a las imágenes que ocasiona, por lo que no puede ser denominada un arte imitativa, sino por sustitución: por medio de los sonidos que surtirían el mismo efecto que la realidad debido a la costumbre. La poesía movería más por simpatía que por fidelidad a lo representado: muestra el efecto de las cosas sobre lamente, antes que presentarnos una idea clara de las mismas. Las palabras influyen sobre las pasiones, porque tomamos una parte extraordinaria en la vida de los otros, cuya existencia nos muestran las palabras; porque nos presentan muchas cosas, que a veces no ocurren en la realidad, causando una gran impresión sobre nosotros; y porque mediante las palabras hacemos combinaciones que no podrían hacerse de otro modo. En suma, movemos a los otros mediante las palabras no a través de sus significaciones, sino por las pasiones que ellas comunican mediante sus sonidos. Estos principios generales se aplican también a la forma como las palabras suscitan en nosotros lo sublime y lo bello.

\section{Lord Kames}

Nació en 1696 en el estado de Kames (Bewirkshire) y falleció el 27 de diciembre de 1782 . Estudió privadamente latín, griego, matemáticas y derecho, y en 1723 se recibió de abogado luego de aprobar los éxamenes correspondientes. Perteneció a la Philosophical Society y a la Select Society de Edimburgo, al igual que Alexander Gerard, y mantuvo una gran amistad con Benjamín Franklin. Su nombre tiene importancia en la historia de la estética por sus Elements of Criticism (1762). La obra tuvo una gran acogida en vida del autor; su edición definitiva, la sexta, apareció en forma póstuma en dos volúmenes en 1785. Comprende una dedicatoria, introducción, veinticinco capítulos y un apéndice. Según Hellen W. Randall es divisible en las siguientes secciones generales: fundamentos de la naturaleza humana (capítulos I-II), principios de las bellas artes (capítulos III-XV), capítulos de tránsito dedicados a principios menores (capítulos XVI-XVII), retórica y poética (capítulos XVIII-XXIII), jardinería y arquitectura (capítulo XXIV) y sobre la norma del gusto (XXV). Seguiremos esta división al exponer la obra.

Kames comienza su introducción recordando la clasificación tradicional de las sensaciones en superiores (la vista y el oído) e inferiores (el tacto, el olfato 
y el gusto), y manifiesta que en verdad aquéllas no son puramente corporales, sino también mentales, aunque no se pueden, sin embargo, equiparar a los placeres intelectuales: en realidad ocupan una posición intermedia entre éstos y los puramente orgánicos. De otra parte, los placeres visuales y auditivos se encuentran distantes tanto de la turbulencia de la pasión como de la languidez e indolencia, por lo que reaniman los espíritus y al mismo tiempo los relajan. En nuestra evolución pasamos de los placeres corporales a los de la vista y el oído, de aquí a los intelectuales y por fin a los morales y de la religión. Por ello existe un interés en cultivar los placeres visuales y auditivos, en especial los que nacen de la poesía, pintura, escultura, música, jardinería y arquitectura. Lord Kames quiere investigar precisamente los principios de las bellas artes, con lo que éstas se convierten en el objeto de una ciencia racional, al igual que la moral, y pueden ser cultivadas con cierto grado de refinamiento. Una crítica de arte racional mejora no sólo nuestro entendimiento, sino también nuestro corazón, vigorizando las afecciones sociales, moderando las egoístas y cosntituyendo un gran soporte para la moralidad. No obstante, en los últimos tiempos la crítica se ha fundado más sobre la autoridad que sobre los principios. De ahí que Kames quiera fundamentar los principios de la crítica filosófica del arte - no todos, pero sí una buena parte de ellos, partiendo de la naturaleza humana-, con lo que quedaría probado que el hombre es un ser sensible capaz de placer y pena. El método que el autor elige para descubrir los principios -influido quizás por Newton-, es inductivo y empírico: ascender de los hechos y experimentos a los principios, en lugar de descender de éstos a aquéllos.

Según lord Kames nuestras percepciones e ideas se encuentran sometidas a la ley de la sucesión y en ellas, al igual que en nuestras acciones, gobierna el principio del orden: pasamos de las causas a los efectos. Estamos pues estructurados por naturaleza para gustar del orden y la sucesión. De ahí que cuando una obra de arte se conforma a nuestro curso de ideas nos causa placer, y disgusto si lo contraría. En consecuencia, una obra de arte tiene que estar construida como un organismo, algo que el autor echa de menos en Homero y Píndaro, en Horacio y Virgilio. De todos los sentimientos provocados en nosotros por los objetos externos son sólo los nacidos de los ojos y oídos a los que se denomina pasiones y emociones; esto explica la conexión entre éstas y las obras de arte, que en cambio no gratifican a nuestros sentidos inferiores. Las palabras y los sonidos tienen un gran poder para provocar pasiones y emociones, y si no sucede lo mismo con la pintura es porque se limita a la representación de un instante. Llamamos agradables o desagradables a los objetos y placenteras o penosas a las emociones que sentimos. Que una emoción sea placentera o penosa depende por entero de su causa: invariablemente la emoción producida por un objeto agradable es placentera y la generada por uno desagradable dolorosa. Una regla general es que hay una 
naturaleza común en cada especie de animales, en particular en la humana, que es correcta o perfecta; en consecuencia, la pasión que se desvíe de ella será incorrecta o desagradable y la que se adecue correcta o agradable. Otra regla es que, si existe un deseo de realizar una acción correcta acompañante de la pasión, ésta será agradable; y, en cambio, si el deseo es cumplir una acción incorrecta, la pasión será desagradable. "Así tanto las pasiones como las acciones están gobernadas por un sentido moral." Las emociones, al igual que el movimiento, "requieren del ejercicio constante de una causa operante, y cesan cuando desaparece la causa". No obstante, y aun cuando ésta no actúe más, subsistirá una pasión en forma más débil por efecto de una idea que la sostiene, hasta que otro pensamiento llene la mente. Las pasiones que surgen súbitamente decaen en la misma forma. No basta estudiar las pasiones de manera aislada, sino que es menester examinarlas en su coexistencia: las semejantes se combinan o unen fácilmente, y las desemejantes con dificultad o no se unen. Sin embargo, pasiones diferentes pueden entrelazarse cuando son producidas por una misma causa, y es por ello que hablamos de "una duke aflicción", de "una pena placentera". Home elabora una complicada casuística sobre la coexistencia de las pasiones y sus causas, y ofrece reglas prácticas que se aplican a las bellas artes, en especial a la música, donde no puede aceptarse una combinación sonora desagradable, una disonancia. El autor también se ocupa de la influencia de las pasiones sobre nuestras percepciones, opiniones y creencias, de la semejanza entre las emociones y sus causas y de las causas finales de las emociones y pasiones - lord Kames cree que Dios las ha puesto en nosotros para promover nuestra felicidad excitando nuestra industria, ya que los seres objeto de nuestras emociones y pasiones son útiles en la vida diaria.

A continuación Kames pasa a examinar cómo sirven las emociones y pasiones en general para desarrollar los principios de las bellas artes. Ya que las cosas son la causa de las emociones por medio de sus propiedades y atributos -pues las cualidades abstractas son demasiado apagadas como para producir ninguna suerte de afección-, el autor analiza cómo ocasionan dichas cualidades nuestros movimientos emocionales. Primero se ocupa de los atributos simples de los objetos individuales y después de los atributos dependientes de las relaciones entre objetos.

Los atributos simples o intrínsecos de los que Kames trata son: a) la belleza; b) la novedad y lo inesperado; c) lo risible y ridículo. Comencemos por el primero. En su significado originario hablamos de belleza en el caso de los objetos de la vista; y en un sentido figurado del lenguaje, los sonidos, los pensamientos o la expresión, un teorema, un evento, un descubrimiento en el arte o en la ciencia. Refirámonos al primer significado. El carácter común de las emociones que provocan la belleza es la dulzura y la alegría. La belleza de los objetos visibles puede ser intrínseca, asunto de los sentidos, y relativa, 
tema del entendimiento o de la reflexión que reconocen para qué es adecuado algo en su uso o destino. Al coincidir ambas bellezas hacen aparecer al objeto en que reposan como placentero: es el caso de las formas simétricas y útiles de un caballo de carreras.

La belleza relativa no necesita de ilustración, lo que sí sucede con la intrínseca debido a su complejidad. Sus partes constituyentes son la figura, el tamaño, el movimiento y el color. Como la belleza del color nos es muy familiar, el autor sólo examina la belleza que proviene de los otros tres elementos. Regularidad, simplicidad, uniformidad, proporción y orden son los atributos particulares que constituyen la belleza de la figura como parte integrante de la belleza intrínseca. ¿Por qué gustamos de estos atributos? Según el autor, es vano el empeño de tratar de responder a esta pregunta, pero cabe suponer que estamos estructurados de tal modo que respondemos placenteramente al percibir estos atributos. Podemos agregar además que el gusto por estas cualidades no es accidental, sino uniforme y universal; y que la proporción se encuentra relacionada en algunos casos con una finalidad útil. La belleza del tamaño se divide en grandeza, sentimiento producido en nosotros por la magnitud, y la sublimidad, sentimiento generado por la elevación. En estos casos el objeto agradable ocupa toda nuestra atención, y sentimos que nos dilata el corazón una emoción íntima, placentera y seria -a diferencia de la emoción de la belleza que es dulce y alegre. Tratar de elevar algo bajo, o temas familiares, sobre su rango mediante una descripción fatigante, da lugar a lo bombástico, lo que en vez de ser sublime resulta ridículo. La belleza del movimiento no obedece a propósito ni designio alguno. Todas las variedades del movimiento son agradables, pero unas más que otras: los movimientos regulares, acelerados, hacia arriba, en línea recta, ondulados y fluidos son preferibles a las alternativas opuestas aunque sea dificil decir por qué. Todo lo anterior no significa que el reposo sea desagradable, sino más bien que nos es indiferente. La fuerza es también agradable como el movimiento, y contribuye a suscitar la impresión de grandeza cuando es mostrada por seres sensibles.

De las circunstancias que provocan las emociones, ni la belleza ni la grandeza tienen una influencia tan poderosa como la novedad. Kames distingue la novedad, que es la emoción maravillosa provocada por un objeto inhabitual, de la admiración, que está dirigida a la persona que opera algo maravilloso; y de la sorpresa, que es una ocurrencia inesperada. Lo novedoso, aunque no sea en sí mismo desagradable, puede llegar a provocar temor -por ejemplo la emoción que despierta un león. Hay grados diversos de la novedad. Una causa final de la maravilla es la emoción que está destinada a estimular nuestra curiosidad, y otra es preparar a la mente a recibir impresiones profundas de objetos desacostumbrados.

Los objetos que hacen nacer en nosotros una emoción peculiar que expresamos externamente con la risa son risibles: se trata de una emoción pla- 
centera y alegre, que distiende la mente recreando los espíritus. Su género es lo absurdo, lo lúdico, deportivo o jocundo. De lo risible hay que distinguir lo ridículo, que añade al acto impropio producido una emoción mixta, "que es aireada con una risa de irrisión o desprecio" hacia el agente del acto. Por otra parte hay que decir que lo risible es una cualidad intrinseca, mientras lo ridículo es una cualidad relativa.

Los atributos relativos son primarios y secundarios según que existan con independencia de nosotros o que dependan de la mente percipiente. Las relaciones secundarias "nacen de objetos conectados por alguna relación primaria". Los atributos primarios a los que Kames analiza son la semejanza y desemejanza, y la uniformidad y pariedad; y los secundarios la congruencia y la propiedad, la dignidad y la gracia y el ingenio.

Nos sentimos gratificados cuando encontramos semejanzas entre objetos diversos, y desemejanzas entre objetos similares. En el fondo, las emociones y pasiones suscitadas por la semejanza y desemejanza están muy influidas por la comparación, que tiene un gran efecto sobre nuestras opiniones.

Podemos considerar la sucesión de nuestras percepciones e ideas desde el punto de vista del orden y la conexión, pero también desde el de su uniformidad y variedad: la cadena de nuestras percepciones $\mathrm{e}$ ideas no depende de nuestra voluntad y posee un movimiento uniforme y variado con una cierta independencia, que obedece a circunstancias como el temperamento, la edad y la nacionalidad. El ritmo natural de la sucesión depende en algún grado de las percepciones particulares que componen la cadena. Un objeto agradable tiene una sucesión más lenta que otro que nos es indiferente. Algunas emociones, empujando la mente de un objeto a otro, aceleran la sucesión. Donde la cadena está compuesta por percepciones e ideas conectadas, la sucesión es rápida. En cambio, la sucesión será lenta si la cadena está formada por percepciones e ideas desconectadas, que no tienen un rápido acceso a la mente; o si un objeto desconectado es admitido con una cierta lucha. Las mismas observaciones son aplicables a las ideas sugeridas por el lenguaje: una idea inconexa toma tiempo para causar una impresión, mientras que si las ideas están interrelacionadas son admitidas rápidamente. De aquí deriva lord $\mathrm{Ka}$ mes una serie de consejos prácticos sobre la conveniencia o inconveniencia de los temas simples o abigarrados y sobre la ornamentación en la pintura; observaciones que extiende a la poesía y la música. Según el autor la definición tradicional de la belleza como "uniformidad en la variedad" es incorrecta, ya que esta cualidad - la variedad - no es un ingrediente necesario de la hermosura en general: no constituye en parte alguna a la belleza de la acción moral, ni a la de un teorema matemático, y son incontables los objetos bellos a la vista que tienen muy poca variedad o no la tienen - por ejemplo un círculo; y un cuadrado es más hermoso que un trapecio, pese a que tienen menos va- 
riedad. No obstante, Kames reconoce que dicha definición tiene también sus aspectos positivos y por eso procura traducirla en términos asociacionistas.

Pasemos ahora a considerar los atributos secundarios y, en primer lugar, la congruencia y la propiedad. Según lord Kames, a diferencia de los animales el hombre posee sentidos delicados como los de la regularidad, el orden, la uniformidad y la congruencia. Por consiguiente, nada es más conveniente al hombre y acorde con su naturaleza que lo que lo lleva a refinar su gusto. La congruencia y la propiedad implican una pluralidad de objetos y significan una relación particular entre ellos. Sentimos agrado cuando encontramos en los objetos una cierta adecuación o correspondencia denominada congruencia o propiedad entre los objetos y desagrado si echamos de menos esta cualidad. El grado de congruencia es proporcionado a la conexión entre las cosas conectadas - como la relación entre un edificio y el terreno sobre el que se levantay entre la conducta y la manera de vivir -el comportamiento recíproco entre los miembros de un club. 'La elegancia es el género, del que la propiedad es una especie: porque no llamamos a nada propio, sino a la congruencia o conveniencia, que debe subsistir entre los seres sensibles y sus pensamientos, palabras y acciones."

La dignidad y la villanía constituyen especies de la propiedad e impropiedad y se aplican a los seres humanos. La dignidad es el sentido del valor y excelencia que el hombre tiene de su naturaleza. La causa final de la dignidad es la condición social del hombre. La gracia es "la apariencia agradable que nace de la elegancia del movimiento y del semblante expresivo de la dignidad. La expresión de otras cualidades mentales no es esencial a esta apariencia, aunque pueda aumentarla mucho." Lo ingenioso es, según nuestro autor, una cualidad de los pensamientos y expresiones, nunca de las acciones y pasiones. El término "cwit" es apropiado a los pensamientos y expresiones absurdas, y por extensión se aplicará a quien tenga un talento para encontrar estos pensamientos y expresiones.

A continuación el autor pasa gradualmente del examen de los principios de las artes al de sus técnicas. Lord Kames considera primero los signos externos de las emociones y pasiones, de los sentimientos y del lenguaje dictado por la pasión. Luego estudia asimismo el lenguaje, plantea una teoría de las comparaciones y figuras, realiza una crítica de los modos de escribir (narración y descripción), y elabora una teoría de los géneros particulares (tragedia y épica). En cada caso formula una serie de reglas prácticas basadas en los principios estéticos, ilustrándolas ya sea cuando se cumplen, como cuando se infringen. Finalmente se refiere a la jardinería y arquitectura, que son artes útiles y bellas.

Por último lord Kames se aboca a la determinación de la norma del gusto, fundamentándola de una manera antropológica. Según él, en nuestra propia especie y en las de los animales hay una naturaleza común, que es un modelo o norma para cada individuo perteneciente a la clase del caso. La naturaleza 
común humana es de acuerdo con Home invariable, universal y perfecta: ha sido, es y será la misma. De allí que cualquier desviación remarcable de esta norma nos provoque correspondientemente una impresión de imperfección, irregularidad o desorden: es desagradable y suscita en nosotros una emoción penosa. Existe sobre la base de esta naturaleza común una norma del gusto en la naturaleza, tanto en el caso de las bellas artes como en el de las cuestiones de la moral. Para indagar las reglas de ambas sólo necesitamos investigar el sentido común de la humanidad en su estado más perfecto. El sentido moral está mucho más desarrollado que el de las bellas artes, porque sus objetos son más claros y distinguibles. Pero ambos, el sentido moral y el estético, están expuestos a la corrupción debido a la voluptuosidad y al egoísmo. En cambio, la educación, la reflexión y la experiencia incrementan estos sentidos, preservándolos en una vida moderada. Por lo demás, las diferencias entre los gustos son menores de lo que habitualmente se cree, aunque lord Kames piensa que es posible un gusto errado o erróneo y asevera que un gusto deficiente es en verdad incurable. Pero estas diferencias conciernen a pequeñeces y pueden ser salvadas recurriendo a los principios del gusto e invocando la inalterable naturaleza humana.

\section{Archibald Alison}

El reverendo Archibald Alison nació en 1757 y falleció en 1839. Estudió en el Balliol College de Oxford y fue prebendario de Sacrum y senior minister de la Capilla Episcopal de Cowgate, Edimburgo. La publicación de Alison que interesa a la historia de la éstetica es Essays in the Nature and Principles of Taste de 1790 , libro que tuvo numerosas reediciones $(1812,1815,1817,1825 \mathrm{y}$ 1842).

La obra se divide en una introducción y dos ensayos. La primera comienza con la sigu:ente definición: "El gusto es, considerado en general, la facultad de la mente humana por la que percibimos y disfrutamos lo que es hermoso o sublime en las obras de la naturaleza o del arte." Según el autor, ciertas cualidades producen en nosotros una mención de placer a la que denominamos emoción del gusto. La distinción de los objetos del gusto en lo sublime y lo bello, hace que en forma semejante se divida a la emoción en emoción de lo sublime y de lo bello. Para descubrir las causas que producen estas emociones no hay otro método que el del experimento paciente y variado. Los objetos de la investigación con respecto al gusto son, por lo tanto, la naturaleza de las cualidades que producen las emociones del gusto y la naturaleza de la facultad por la que estas emociones son percibidas.

Alison considera que las teorías tradicionales sobre el gusto han errado por considerar que la emoción es muy simple, por lo que han referido dicha facultad a un único principio o ley de la mente humana: ya sea a un sentido o 
sentidos peculiares, con lo que han aterdido sobre todo a la causa de las emociones de lo sublime y de lo bello y no a su naturaleza; o han referido el gusto a uno de los principios de la condición humana, con lo que han considerado su naturaleza, pero no su causa. Alison estima que hay que examinar ambos aspectos, por lo que plantea dividir su investigación en tres partes:

I. El análisis de los efectos producidos en la mente cuando se sienten las emociones de lo bello y de lo sublime. Este efecto es diferente, según el autor, de la determinación de un sentido, y no es el efecto de una emoción simple sino compleja. Se debe mostrar el origen de la belleza y la sublimidad en cualidades de la materia; éstas no son bellas o sublimes en sí mismas, pero constituyen los signos o expresiones de cualidades capaces de producir emoción.

II. La investigación de las causas que producen las emociones de lo bello y de lo sublime. Accesoriamente, en esta parte se debe indagar cómo se encuentra lo bello y lo sublime, no sólo en lo que produce placer, sino también en lo que causa pena; y la naturaleza de la distinción entre lo bello y lo sublime.

III. La naturaleza de la facultad del gusto: no tiene semejanza con un sentido; cada vez que se emplea se utilizan dos poderes distintos $\mathrm{e}$ independientes y tiene que ser resuelta en principios más generales de nuestra constitución.

Todas estas investigaciones tienen que desembocar en la indagación de la norma del gusto.

En realidad, los Essays in the Nature and Principles of Taste sólo cubren la primera parte de este programa, aunque permiten entrever lo que Alison pensaba sobre las otras dos partes. "Podemos considerar los Essays... existentes como si constituyeran la base del perfil del sistema entero. El sistema es desarrollado especificando en forma tan cerrada como sea posible las dos variables de una teoría asociacionista - las ideas e impresiones componentes y las relaciones que las conectan.” (W. J. Hipple.)

El primer ensayo trata "De la naturaleza de las emociones de la sublimidad y la belleza" y comprende dos capítulos. El primero se ocupa "Del efecto producido por los objetos de la sublimidad y belleza sobre la imaginación”. Según Alison: "cuando se sienten las emociones de la sublimidad y belleza se produce el ejercicio de la imaginación consistente en la promoción de una cadena de pensamientos; en cuanto este ejercicio es impedido estas emociones no se sienten o no se perciben; y [...] lo que tiende a incrementar este ejercicio de la mente, tiende a incrementar estas emociones en la misma proporción [... En consecuencia,] el efecto producido sobre la mente por los objetos de la sublimidad y la belleza consiste en la producción de este ejercicio de la ima- 
ginación.” El autor cree que cuando a un hombre se le presenta lo sublime o lo bello, se le despierta una cadena de pensamientos en la imaginación, cadena análoga al carácter o expresión del objeto original. Así, cuando experimentamos lo sublime de los cuadros de Lorrain, de la música de Händel o de la poesía de Milton, nuestra imaginación cstá encendida por sus poderes y nos perdemos a nosotros mismos en el sinnúmero de imágenes que pasan ante nuestras mentes; cuando despertamos, es como si saliéramos de un sueño romántico. Pero este ejercicio de la imaginación puede ser bloqueado por la pena, la aflicción, el recuerdo; asimismo por la crítica o las diferencias de carácter -hay personas más dispuestas al ejercicio de la atención que al de la imaginación. Por otro lado, el progreso de la vida priva a los seres humanos de su sensibilidad hacia los objetos del gusto.

Ahora bien, Alison sostiene que es demasiado general afirmar que para la producción de las emociones del gusto son necesarios el ejercicio de la imaginación y la promoción de las cadenas de pensamientos. Lo que se requiere es precisar qué cadenas van acompañadas de placer y de las emociones correspondientes de la sublimidad y la belleza. Esta diferencia consiste en dos cosas: 1) en la naturaleza de las ideas o concepciones que componen dichas cadenas, y 2) en la naturaleza o ley de la sucesión. Por su naturaleza dichas ideas no son indiferentes - como las ideas de las cadenas ordinarias-, y su ley de sucesión es un principio general de conexión subsistente a través de toda la extensión de la cadena, el cual otorga a los pensamientos un carácter cierto y definitivo: "Ellos son alegres o patéticos, melancólicos o solemnes, terribles o elevados y así sucesivamente, de acuerdo con la naturaleza de la emoción que primero se excita." En cambio, en nuestras cadenas ordinarias raramente aparece algún principio general de conexión, sino que cada idea sólo está referida a la que la precede de inmediato. Los objetos a los que denominamos bellos o sublimes son sentidos como productores de alguna emoción simple y no como indiferentes o ininteresantes; y las ideas correspondientes de las cadenas de pensamiento producidas por los objetos bello o sublimes son ideas de emoción. De esta manera termina el capítulo segundo "Análisis de este ejercicio de la imaginación”, ejercicio que produce las emociones de la belleza y la sublimidad.

El segundo ensayo trata "De la sublimidad y belleza del mundo material". El autor escribe que no hay duda de que muchos objetos del mundo material producen emociones sublimes y bellas; pero que, por otro lado, hay que conceder que en sí misma la materia es inadecuada para producir cualquier clase de emoción. No obstante, es obvio que aunque esto sea cierto, las cualidades de la materia pueden producir este efecto asociándose con otras cualidades -las mentales- y siendo los signos o la expresión de las cualidades apropiadas (fitted), debido a la constitución de nuestra naturaleza, para producir emoción. Así, en el cuerpo humano, las formas particulares o colores son los 
signos de pasiones o afecciones particulares; en las obras de arte, las formas particulares son signos de las destreza, del gusto, de la conveniencia y de la utilidad; y en las obras de la naturaleza, los sonidos y colores particulares son signos de paz, de peligro, de abundancia, de desolación, etc. "En tales casos, la conexión constante que descubrimos entre el signo y la cosa significada, entre la cualidad material y la cualidad productiva de la emoción convierte finalmente a la una en expresiva de la otra para nosotros, y muy a menudo nos dispone a atribuir al signo aquel efecto que es producido sólo por la casualidad significada."

En la conclusión del segundo ensayo, el autor resume el contenido de éste al ofrecer sus conclusiones:

Las ilustraciones que han sido expuestas en el curso de este ENSAYO sobre el origen de la SUBLIMIDAD y la BELLEZA de algunas de las principales cualidades de la MATERIA, parecen aportar la siguiente evidencia para estas conclusiones:

I. Que cada una de estas cualidades es - ya sea por naturaleza, por experiencia o por accidente- el signo de alguna cualidad capaz de producir emoción o el ejercicio de alguna afección moral. Y

II. Que cuando estas asociaciones son disueltas o, en otras palabras, cuando las cualidades materiales cesan de ser significantes de las cualidades asociadas, cesan también de producir las emociones de la sublimidad o de la belleza.

Si estas conclusiones son admitidas, parece necesario colegir que la belleza y la sublimidad de tales objetos hay que adscribirlas no a las cualidades materiales mismas, sino a las cualidades que éstas significan; y es una consecuencia que las cualidades de la materia no pueden ser consideradas como sublimes o bellas en sí mismas, sino al ser los SIGNOS o EXPRESIONES de cualidades tales que, por la constitución de nuestra naturaleza, son apropiadas (fitted) para producir emociones placenteras o interesadas.

Las cualidades de la materia significantes de las cualidades productoras de la emoción a las que Alison considera, son las percibidas por los sentidos, a los que la tradición ha considerado como estéticamente importantes: el oído y la vista.

Los objetos del primero son SONIDOS sean SIMPLES o COMPUESTOS. Los objetos del segundo son COLORES, FORMAS o MOVIMIENTOS.

De acuerdo con este criterio, el segundo ensayo está dividido en capítulos que estudian sucesivamente la sublimidad y belleza de los sonidos, de los colores, de las formas y del movimiento. A este examen de la materia inanimada en relación con su capacidad para suscitar emociones estéticas, se añade una consideración sobre el origen de la belleza y la sublimidad que percibimos en el semblante y forma del hombre. 
En la parte final del libro, Alison se refiere a las causas finales de la constitución de nuestra naturaleza. Nuestra curiosidad no está satisfecha, sostiene,

hasta que termine en el descubrimiento no sólo del designio (design), sino también de un designio benevolente: y la gran ventaja [...] que uno deriva de la indagación de las leyes de la propia mente, es mucho menor en la adición que ofrece al propio poder o sabiduria que en la evidencia que le proporciona de la sabiduría con la cual ha sido forjada su constitución y los magníficos propósitos para los cuales ha sido formada.

Los propósitos del creador son, entre otros, la distribución general e imparcial de la felicidad (la cual sería arbitraria y caprichosamente limitada si la belleza fuera "objetiva”) y el estímulo perpetuo de las artes mecánicas y liberales (pronto llegariamos a una situación estática si se lograra alguna vez una belleza "objetiva"). Lo más importante es que, como las emociones del gusto están mezcladas con los sentimientos morales, los placeres del gusto conducen al mejorainiento moral. Así sucede que, mientras los objetos del mundo material están hechos sólo para atraer nuestros sentidos materiales, las experiencias estéticas son adecuadas para despertar en nosotros emociones morales. A fin de cuentas, "la naturalezsten todos los aspectos alrededor nuestro debe ser sentida sólo como un signo de [...] la providencia [del creador] y que nos conduce, por la fuerzo universal de estos signos, al trono de la DEIDAD”.

\section{Consideración final}

Podemos dividir la estérica británica del siglo XVIII en tres fases: 1) la reacción ante las ideas de Locke: negativa en Shaftesbury y positiva en Addison, Hutcheson y Gerard. Es legítimo sostener que estos dos últimos buscaron a su modo realizar los lineamientos de la filosofia lockeana -en sus intenciones, mas no en sus planteamientos; Hutcheson tomó como modelo el funcionamiento de los sentidos externos para postular un sentido interno de la belleza (y otro de la moral). Sin embargo, este sentido operaba en forma muy poco empírica, contrariando principios elementales de la filosofía de Locke. Las consecuencias nefastas de esta posición se harían visibles cuando, en el mismo Hutcheson último y después con mayor claridad en Gerard, los sentidos internos comenzaron a multiplicarse indeteniblemente. 2) La estética más empirista de Hume, que llegó a ciertos extremos fisiologistas en Burke. 3) La fase decididamente asociacionista que se muestra en Kames y Alison - y en cierta manera también en Burke. Un lugar aparte le corresponde a Hogarth, cuyo The Analysis of Beauty es el tratado técnico de un pintor y sobre todo grabador que también contiene principios estéticos - del mismo modo que sucede en los Discursos sobre el arte de J. Reynolds, que no hemos podido tratar. 
K. E. Gilbert y Helmuth Kuhn señalan en su $A$ History of Esthetics que tan promisorio en planteamientos estéticos nuevos como era el "new way of ideas" de Locke, luego de examinar los puntos de vista de los pensadores que lo recorrieron, se advierte que los resultados logrados por la Escuela Británica no son tan inesperados y ni tan distintos de los del racionalismo francés: "Mas luego de seguir todas las variedades de expresiones y notas definidas de rebelión en la nueva Escuela Británica contra las 'reglas', uno se ve forzado a admitir que el parentesco del 'gusto' que encontraron - con base en el sentido interno, del sentimiento, la pasión o la intuición-es mayor con las reglas neoclásicas de Boileau que con el relativismo espacial y temporal de Ogier. Estos escritores trabajaron con un nuevo mecanismo - el marco de la naturaleza humana-, pero a la largo resultó un producto que difiere sorprendentemente poco de aquel al que se ajusta el racionalismo cartesiano. ¿Por qué no concluyó de una manera radical el camino radical? En parte porque la autoridad práctica del gusto francés originada en la época de Boileau dominó la Gran Bretaña en la primera mitad del siglo XVIII [... E En parte [... porque] el contenido del juicio estético, cualquiera que fuera su mecanismo, fue tomado de la tradición."

No estamos de acuerdo con el juicio de estos dos meritorios historiadores de la estética. Encontramos que tienen una representación falsa del curso de una revolución estética: suponen que a su término deberían haber cambiado radicalmente las valoraciones vigentes impuestas por el racionalismo francés; y pensamos que descuidan modificaciones importantes concernientes a las categorías estéticas y a su fundamentación. Por una parte, luego de la labor desplegada por la estética británica del siglo XVIII, quedó conmovido y alterado el conjunto de criterios que se aplicaban a la valoración de los estilos literarios y literaturas nacionales. Hay que tener presente a este respecto que el Clasicismo francés se sentía heredero de lo mejor de la tradición grecolatina y menospreciaba a las otras tradiciones nacionales - la inglesa, italiana, española y, por cierto, a la alemana, que por entonces era casi inexistente (recuérdese a este respecto las invectivas de Sorbière y del P. Bouhours). En este sentido, Shakespeare o Milton no podían contender con Homero o Racine. Esto no era de extrañar: si se defendían criterios de excelencia literaria como el orden, la mesura y el equilibrio, tenía que concluirse así. Pues bien, luego de la acción, este panorama había cambiado: autores como Addison o lord Kames introdujeron nuevos criterios que alteraron enormemente los juicios clásicos. Pero, claro está, sería absurdo que esta alteración hubiera significado negar en bloque la tradición anterior. Significaba más bien un reordenamiento relativo, hacer campo para otras literaturas nacionales además de la francesa (literaturas que no se ajustaban a los criterios extraídos de la tradición grecolatina) y reivindicar sus méritos.

Por otra parte, al sostenerse que era el estudio de la naturaleza humana el indicado para fundamentar los juicios de valor o la norma del gusto, se sub- 
vertía el fundamento de la crítica anterior y se contribuía a la subjetivización acelerada de la estética. ¿En qué consiste ésta? En un sentido preciso, en lo siguiente: la estética antigua, medieval y parte de la renacentista había fundado lo bello o las otras categorías estéticas sobre propiedades de las cosas. En la estética moderna se va a sostener más bien que lo bello -o las otras categorías estéticas- es algo que no se encuentra en el ámbito del objeto sino del sujeto. Son cualidades de los objetos, en verdad, las que desencadenan en nosotros la "experiencia" de lo bello. Pero lo bello o lo sublime no son, como Alison subraya, cualidades de las cosas bellas, sino ciertas características materiales como el color o la figura -éste es su planteamiento particular- que asociadas con cualidades mentales nuestras dan lugar a la percepción de lo bello o de lo sublime. La captación de las emociones correspondientes-de lo bello o de lo sublime - tiene como rasgo peculiar un ejercicio de la imaginación consistente en la promoción de una cadena de pensamientos.

Por lo demás, cambian las categorías estéticas y su fundamentación. Ésta se encuentra en la naturaleza humana: en cierto sentido interno, los sentimientos, la intuición. Cobra entonces una gran importancia la asociación y se psicologiza la estética. Y, por otra parte, la belleza pierde en importancia frente a lo sublime y a otras categorías nuevas que aparecen por entonces: la novedad, el refinamiento, la magnificencia, lo bombástico, lo pintoresco.

La extrema importancia de los planteamientos de la Escuela Británica se advierte en la reivindicación de la imaginación como la primera facultad creadora humana, en su concepción del genio y de la genialidad -que luego tendría una importancia decisiva en todos los movimientos románticos europeosy en el hecho de que haya expuesto a la estética al peligro del escepticismo, que posteriormente trataría de combatir y superar Kant. En verdad, después del siglo XVIII británico todo el panorama de la estética aparece totalmente cambiado. 
Esta fé de erratas se publicó en el número 38, de 1992 .

\section{NOTAS}

En el número anterior de Diánoia (vol. 37, núm. 37, corresponiente a 1991), en el artículo "La estética británica del siglo XVII" de David Sobrevilla aparece como sede Instituto Goethe de Lima, debe decir: Universidad de San Marcos (Lima).

En ese mismo artículo se omitió la bibliografía que a continuación se presenta:

Bibliografía

\section{General}

Anceschi, Luciano, L'estetica del empirismo inglese, t. I., Da Bacone a Shaftesbury, Alfa, Boloña, 1959.

Bate, Walter Jackson, Form Classic to Romantic. Premisses of taste in Eighteenth-Century England, Harvard University Press, Harvard, 1946.

Cassirer, Ernst, Die platonische Renaissance in England und die Schule von Cambridge, Teubner, Leipzig/Berlín, 1932.

- Filosofia de la Ilustración, Fondo de Cultura Económica, México, 1950.

Folkierski, W., Entre le Classicisme et le Romantique. Étude sur l'Esthétique et les Estheticiens du XVIIIe Siècle, Champion, París, 1925.

Formigari, Lia, LEstetica del Gusto nel settecento inglese, Sansoni, Florencia, 1962.

Gilbert, K.E. y H. Kuhn, A History of Aesthetics, Dover, Nueva York, 1972.

Hipple Jr., Walter John, The Beautiful, the Sublime and the Picturesque in EighteenthCentury British Aesthetic Theory, The Southern Illinois Press, Carbondale, 1957.

Horn, András, Geschichte der anthropologischen Fragestellung in der englischen Ästhetik von Bacon bis Alison, Lang, Berna, 1976.

Mirabent y Villaplana, F, La estetica inglesa del siglo XVIII, Barcelona, 1927.

Rossi, Mario, L'Estetica dell'Empirismo Inglese, Florencia, 1944, 2 vols.

Von Stein, K. Heinrich, Die Entstehung der neueren Ästhetik, Olms, Hildesheim, 1964.

2. Específica

1) Shaftesbury

Shaftesbury, Characteristics of Men, Manners, Opinions, Times, ed. con notas de John M. Robertson, The Bobbs-Merrill, Indianapolis, 1964, vol. I-II.

Brett, R.L., La filosofia de Shaftesbury y la estética literaria del siglo XVII, Facultad de Filosofia y Humanidades de la Universidad Nacional de Córdoba, Buenos Aires, 1959. 
Stolnitz, Jerome, "On the Significance of Lord Shaftesbury in Modern Aesthetic Theory", The Philosophical Quarterly, vol. II, no. 43, abril de 1961, pp. 97-113.

2) Addison

Addison, Joseph y Richard Steele, The Spectator, ed. de Donald F. Bond, Clarendon Press, Oxford, 1965, vol. III.

Addison, Joseph, "Los placeres de la imaginación", en Filosofia del arte, trad. cast. de A. Álvarez V., Morata, Madrid, 1968, pp. 109-166.

Thorpe, C.D., "Addison's Theory of Imagination as 'Perceptive Response'", en Paper of the Michigan Academy of Sciences, Arts and Letters, Ann Arbor, Michigan, 1936, vol. XXI, pp. 509-530.

\section{3) Hutcheson}

Hutcheson, Francis, An Inquiry concerning Beauty, Order, Harmony, Design, ed. de P. Kivy, M. Nijhoff, La Haya, 1973.

Kivy, Peter, The Seventh Sense. A Study of Francis Hutcheson's Aesthetics and Its Influence in Eighteenth-Century Britain, Burt Franklin, Nueva York, 1976.

4) Hume

Hume, David, A Treatise of Human Nature, ed. de L.A. Selby-Bigge, At the Clarendon Press, Oxford, 1940.

$\longrightarrow$ Enquiries Concerning Human Understanding and Concerning the Principles of Moral, ed. de L.A. Selby-Bigge, rev. de P.H. Nidditch, At the Clarendon Press, Oxford, 1975.

- Of the Standard of Taste and Other Essays, ed. de John W. Lenz, The BobbsMerrill, Indianapolis, 1977.

Brunet, Olivier, Philosophie et Esthétique chez David Hume, A.G, Nizet, París, 1966.

5) Hogarth

Hogarth, William, The Analysis of Beauty. Written with a View of Fixing the Fluctuating Ideas of Taste, Olms, Hildesheim; 1974.

6) Gerard

Gerard, Alexander, An Essay on Taste, ed. facsimilar de la 3a. ed. de 1780, introd. de W.J. Hipple Jr, Gainesville, Scholar's Fascimiles and Reprints,Florida, 1963.

- An Essay on Genius, Londres, 1774.

Greene, Marjorie, "Gerard's Essay on Taste", Modern Philology, vol. XII, agosto de 1943, pp. 45-58.

7) Burke

Burke, Edmund, A Philosophical Enquiry with the Origin of our Ideas of the Sublime and Beautiful, ed. de J.T. Boulton, Routledge \& Kegan Paul, Londres, 1958.

- Indagación filosófica sobre el origen de nuestras ideas acerca de lo sublime y lo bello, trad. de don Juan de la Dehesa, Valencia, 1985.

8) Lord Kames

Lord Kames, Elements of Cristicism, sexta edición con las correcciones y adiciones del autor, Edimburgo, 1785, 2 vols. 
Randall, Helen Whitecomb, The Critical Theory of Lord Kames, Smith College Studies, Northhampton (Mass.), 1944.

9) A. Alison

Alison, A., Essays on the Nature and Principles of Taste (1790), Olms, Hildesheim, 1968.

El maestro Javier Esquivel, quien fuera investigador y Secretario Académico del Instituto de Investigaciones Filosóficas, falleció el 25 de octubre de 1992. Diánoia lamenta profundamente la pérdida de su cercano colaborador. 